\title{
Microwave plasma jet in water: effect of water electrical conductivity on plasma characteristics
}

Ahmad Hamdan1,*, Jacopo Profili1, and Min Suk Cha2

1 Groupe de physique des plasmas, Département de Physique, Université de Montréal, C.P. 6128, Succ. Centre-ville, Montréal, Québec, H3C 3J7, Canada

2 King Abdullah University of Science and Technology (KAUST), Clean Combustion Research Center (CCRC), Thuwal 23955, Saudi Arabia

* Corresponding author: Email: ahmad.hamdan @umontreal.ca

Keywords: Microwave plasma, plasma in water, plasma in bubbles, electrical conductivity, high-speed imaging, optical emission spectroscopy. 


\begin{abstract}
Plasma-induced water treatment is a novel water treatment technique that has shown high efficiency and flexibility. Although the electrical conductivity of impure water varies depending on the degree of pollution, its influence on plasma treatment efficiency is not well understood. In this study, we investigate the fundamentals of a microwave plasma jet submerged in water with electrical conductivities $\left(\sigma_{\mathrm{w}}\right)$ ranging from 10 to $10000 \mu \mathrm{S} / \mathrm{cm}$. The plasma characteristics, namely composition, electron density, and temperature, and their variations as a function of $\sigma_{\mathrm{w}}$, are derived using optical emission spectroscopy. The plasmabubble dynamics is investigated using space- and time-resolved high-speed imaging. The results show that the plasma fills the bubble volume at relatively low flow rate (typically, $<2$ $\mathrm{L} / \mathrm{min}$ ) and high $\sigma_{\mathrm{w}}$ (typically, $>1000 \mu \mathrm{S} / \mathrm{cm}$ ). The influence of $\sigma_{\mathrm{w}}$ on the degradation of methylene blue, a standard water pollutant, is also assessed, and the obtained results indicate that the plasma becomes extremely inefficient at high $\sigma_{\mathrm{w}}$. These findings are of great importance for the community of plasma-induced liquid processing, particularly wastewater treatment.
\end{abstract}




\section{INTRODUCTION}

Plasmas in- or in-contact with a liquid medium constitute a novel field of research that presents great potential for numerous applications, such as material processing [1]-[3], wastewater treatment [4], agricultural engineering [5]-[7], medical treatment [8]-[10], and others. To date, various plasma sources have been designed, developed, and studied for liquid processing. These can be classified into two categories: thermal (high temperature for all species - thousands of degrees kelvin) and non-thermal (high temperature for electrons - thousands of degrees kelvin and low temperature for neutrals and ions-hundreds of degrees kelvin) [11]. Such (thermal and non-thermal) plasma sources can be powered using direct current (DC) [12], alternative current (AC) [13], and pulsed power [14] electrical excitation, as well as high-frequency electromagnetic fields (microwave and radio frequency) [15] and lasers [16]. Some plasma sources utilize electrodes, such as corona discharge, dielectric barrier discharge, spark, and arc discharge, whereas others are electrodeless, such as radio frequency and microwave discharge that use induced-field, antenna, or wave guide for coupling the power to a gas flowing in a dielectric tube.

In a plasma-assisted-water-treatment setup, it is preferable that a plasma-electrode interaction is minimized to avoid secondary contamination due to electrode's erosion [17]-[19]. Such erosion can contaminate the water with nanoparticles whose hazards are not clearly known. Recently, a submerged arc jet system has been proposed to generate plasmas that are independent of liquid properties [20], and it has been reported to effectively decompose phenols. However, as the use of metallic electrodes is essential for the arc discharges, there are strong plasma-electrode interactions leading to both decreased lifetime of the plasma device and the secondary contamination of water by metallic particles. In a subsequent study, a submerged electrodeless microwave plasma jet was designed to avoid such secondary contamination due to electrode erosion [21]. The system showed great potential for water processing as compared to other processes [22].

When a discharge location is geometrically decoupled from a target liquid as shown with the submerged arc jet [20] and the microwave plasma jet [21], we should investigate how liquid properties affect remotely generated plasmas. The influence of water conductivity, as an example, has been addressed in literature under various conditions. In this context, Bruggeman et al. [12] 
have investigated its influence (by adding $\mathrm{KCl}$ ) on the properties of a DC discharge in liquid. A change in the discharge mode is observed: streamer-like discharge in liquid is observed at low conductivity, whereas streamer discharge in liquid vapor is observed at conductivity higher than $\sim 45 \mu \mathrm{S} / \mathrm{cm}$. They also showed that, as liquid conductivity is increased from 1 to $700 \mu \mathrm{S} / \mathrm{cm}$, the breakdown voltage is decreased from $\sim 11$ to $1 \mathrm{kV}$ and the electron density is decreased from $\sim 10 \times 10_{20}$ to $3 \times 10_{20} \mathrm{~m}-3$. Recently, Wang et al. [14] have investigated the influence of liquid

conductivity (by adding $\mathrm{KCl}$ ), in the range 10-36000 $\mu \mathrm{S} / \mathrm{cm}$, on the properties of a nanosecond pulsed discharge in bubbled water (the used gases are He or Ar). They showed that the production rate of $\mathrm{H}_{2} \mathrm{O}_{2}$ was not significantly changed with liquid conductivity when He gas is used, however, it decreased by $\sim 13 \%$ when Ar gas is used. Using an equivalent-circuit model, they also showed that decrease in the rise time of the applied voltage increased the breakdown voltage and improved the tolerance of the plasma system to the liquid conductivity allowing it to function in sea-water. The effect of water's electrical conductivity on the physical characteristics of electrical discharges in water with Ar gaseous bubbles is also studied by [16], and they reported, among others, that the discharge probability is reduced by $46 \%$ as the conductivity is increased from 10 to $1000 \mu \mathrm{S} / \mathrm{cm}$. In this context, it is clear that electrical conductivity has a great influence on in-liquid plasma properties and, therefore, on the induced physics and chemistry for required applications.

In this regard, the present study investigates the effect of water's electrical conductivity (by adding $\mathrm{KCl}$ ) on the physical characteristics of remotely generated microwave plasma jet (MWPJ). We characterize the plasma using optical emission spectroscopy and use a high-speed camera to investigate the relative plasma-bubble dynamics. To address the efficiency of the MWPJ to degrade organic pollutants present in conductive liquids, we use methylene blue as a reference pollutant and monitor its degradation rate under various plasma conditions. Such research is particularly important considering that wastewater has a wide range of electrical conductivity (e.g., $\sim 2-4 \mathrm{mS} / \mathrm{cm}$ for cooling water and $\sim 30 \mathrm{mS} / \mathrm{cm}$ for ballast water [4]).

\section{EXPERIMENTAL METHODS}

\subsection{Setup Design and Working Conditions}

Figure 1Figure 1 depicts the scheme of the experimental setup. A solid-state microwave generator (Sairem, GMS200W) was used to deliver continuous microwave power (at $2.45 \mathrm{GHz}$ ) 
to a surfatron device (Sairem, Surfatron60) using a coaxial cable. The surfatron's temperature was maintained by circulation of chiller-cooled water at $20^{\circ} \mathrm{C}$, as well as a flow of dry air-cooled gas. The gaseous mixture is composed of argon and nitrogen (99.999\% pure), and it flows through a quartz tube with outer and inner diameters of 6.0 and $4.0 \mathrm{~mm}$, respectively. Mass flow controllers were used to control the rate of gas flow through the quartz tube and into a liquid cell (square cylinder quartz) filled with water where it generates bubbles.

To evaluate the effect of electrical conductivity $\left(\sigma_{\mathrm{w}}\right)$ on plasma characteristics and on methylene blue degradation efficiency, five samples of water solutions with different $\sigma_{\mathrm{w}}(10,100$, 1000,5000 , and $10000 \mu \mathrm{S} / \mathrm{cm}$ ) were prepared by adding specific amounts of $\mathrm{KCl}$ to distilled water $\left(\sigma_{\mathrm{w}}=10 \mu \mathrm{S} / \mathrm{cm}\right)$. The conductivity of water was measured using a conductivity meter (Mettler Toledo, Inlab 731-ISM).

A high-speed camera (LaVision, Image Pro HS) was used to study plasma-bubble dynamics. A diode lamp (Luminus, SST-90) was used to illuminate the backside of the liquid cell and to identify the interface between bubbles and the liquid. Exposure time and acquisition frequency were set to $0.47 \mathrm{~ms}$ and $2 \mathrm{kHz}$, respectively, with a spatial resolution of $1056 \times 1312$ pixels. Emission spectra were acquired using a spectrometer (Princeton Instruments, SP2750) equipped with a grating (900 grooves/mm, blazed at visible) and an ICCD camera (PI-MAX3). The spectra were acquired at an exposure time of $1 \mathrm{~ms}$, and 50 spectra were averaged for each sample.

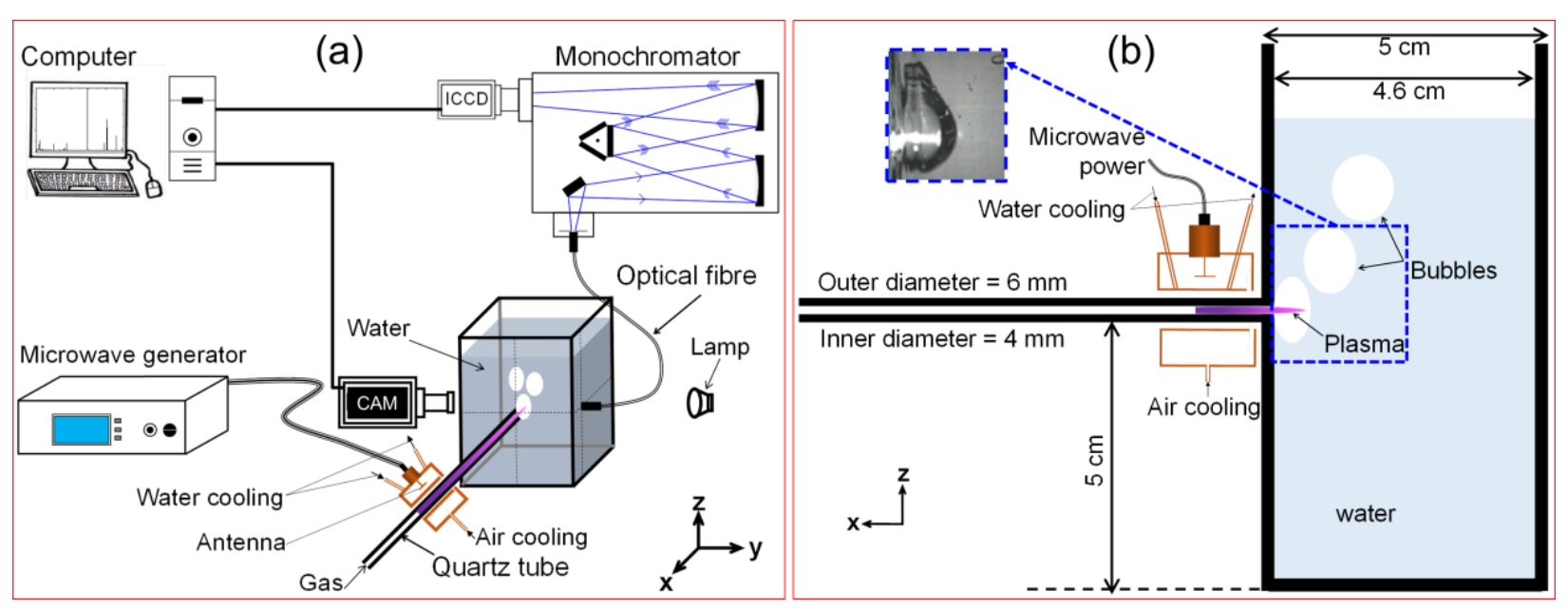

Figure 1. Schematic of the experimental setup used to create submerged MWPJ: a) $3 D$ view and b) $2 D$ view. The zone delimited by dashed-blue line shows where the high-speed images are acquired. 
Methylene blue (MB) was selected as a standard pollutant, and was added to water samples at a concentration of $50 \mathrm{mg} / \mathrm{L}$. The MWPJ-induced degradation of MB was monitored by absorption spectroscopy using UV-Vis spectrophotometer (ThermoScientific, Genesys 10S) in the wavelength range of 350-1100 $\mathrm{nm}$. The decoloration rate of $\mathrm{MB}$ was determined based on absorbance measurements at $663 \mathrm{~nm}$. The shown values are an average of two series of measurements.

\subsection{Determination of Gas Temperature and Plasma Electron Density}

The rotational temperature $\left(T_{\text {rot }}\right)$ of $\mathrm{OH}$, that are supposed to have a Boltzmann distribution, was calculated by fitting its experimental spectrum, according to the method developed by Rodrigo et al. [23]. More details about the developed method and the various assumptions can be found in [23]. Although $\mathrm{OH}$ rotational temperature is very sensitive to the excitation and de-excitation mechanisms occurred in the plasma (a non-Boltzmann distribution can also be obtained), its consideration to represent gas temperature is not straightforward. In our case, we used $\mathrm{OH}$ rotational temperature as a first approximation to conduct a relative comparison between the different values of temperature and to establish a relationship between $T_{\text {rot }}$ and $\sigma_{\mathrm{w}}$. Good agreement between the simulated and the experimental spectra was usually observed, as illustrated in Figures $2 \mathrm{a}$ and $2 \mathrm{~b}$ that correspond to the lowest $\left(T_{\text {rot }} \sim 2245 \mathrm{~K}\right.$; at $\sigma_{\mathrm{w}}=100 \mu \mathrm{S} / \mathrm{cm}, 2$ $\mathrm{L} / \mathrm{min})$ and the highest $\left(T_{\text {rot }} \sim 3500 \mathrm{~K}\right.$; at $\left.\sigma_{\mathrm{w}}=10000 \mu \mathrm{S} / \mathrm{cm}, 0.6 \mathrm{~L} / \mathrm{min}\right)$ temperatures, respectively. Although each experimental spectrum is averaged over 50 accumulations, the error on temperature values has been deduced from the fit quality.
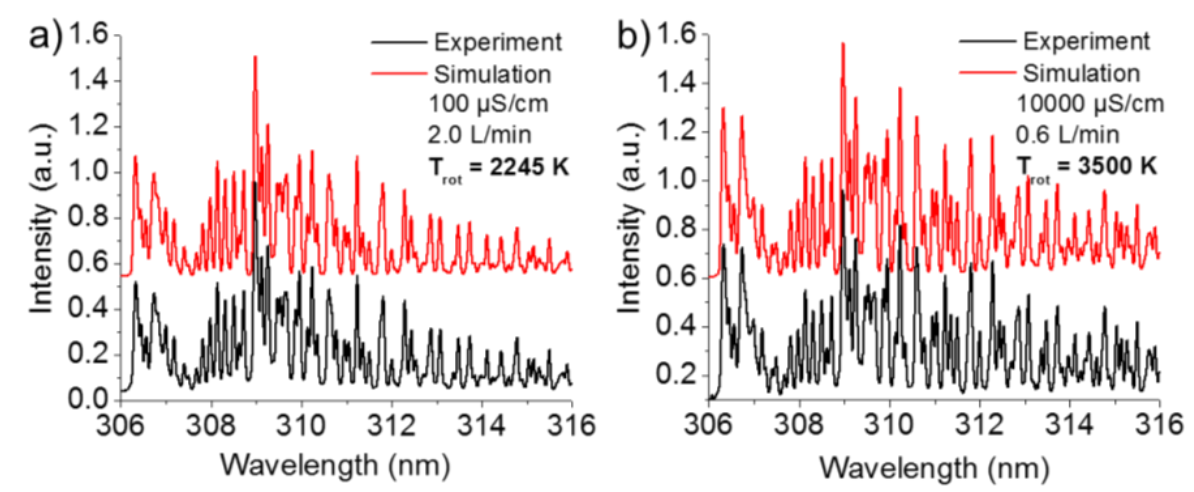

Figure 2. Comparison of experimental and simulated spectra of $\mathrm{OH}(A-X)$ at a) Ar flow rate $=2 \mathrm{~L} / \mathrm{min}$ and $\sigma_{w}=100 \mu \mathrm{S} / \mathrm{cm}$, as well as b) Ar flow rate $=0.6 \mathrm{~L} / \mathrm{min}$ and $\sigma_{w}=10000 \mu \mathrm{S} / \mathrm{cm} ; P=200 \mathrm{~W}$ and water volume $=200 \mathrm{~mL}$. 
The variation of plasma electron density $\left(n_{e}\right)$ as a function of $\sigma_{\mathrm{w}}$ was estimated through a detailed analysis of the $\mathrm{H} \beta$ line $(\lambda=486.1 \mathrm{~nm}, n=4 \rightarrow n=2)$. The spectral shape of an excited species' emission line may be related to certain physical phenomena occurring in the plasma, mainly Doppler effect, van der Waals interactions, and Stark effect. Other factors that influence spectral shape include instrumental broadening and natural broadening. The FWHM (Full Width at Half-Maximum) of Gaussian shaped spectral lines affected by instrumental broadening was determined using a low-pressure light source and was found to be $0.054 \mathrm{~nm}$. Natural broadening, on the other hand, originates from uncertainties in energy (Heisenberg's uncertainty principle), and it is usually negligible compared to other factors affecting spectral line breadth.

Doppler broadening $\left(\Delta \lambda_{\text {Doppler }}\right)$ and van der Waals $\left(\Delta \lambda_{\text {Van der Waals }}\right)$ broadening are given by equations (1) [24] and (2) [25], respectively,

$$
\begin{aligned}
& \Delta \lambda_{\text {Doppler }}(\mathrm{nm})=3.4804 \times 10^{-4} \sqrt{T(K)} \\
& \Delta \lambda_{\text {Van der Waals }}(\mathrm{nm})=5.24 /(T(K))^{0.7}
\end{aligned}
$$

where $\lambda$ is wavelength and $T$ is temperature (assumed to be equal to $T_{\text {rot }}$ ). Broadening induced by Doppler effect (due to temperature) results in a Gaussian profile of the spectral emission lines, whereas broadening induced by van der Waals effect (due to pressure and temperature) yields a Lorentzian profile.

Stark broadening $\left(\Delta \lambda_{\text {Stark }}\right)$ is due to the interaction between emitting species and surrounding charged species (electrons and ions) through their dynamic micro-electric field. Stark broadening of the $\mathrm{H} \beta$ line has been theoretically investigated by Gigosos and Cardenoso [26], and the extensively used relationship between $n_{e}$ and $\Delta \lambda_{\text {Stark }}$ is given by equation (3) [24]:

$$
n_{e}\left(\mathrm{~cm}^{-3}\right)=10^{16} \times\left[\Delta \lambda_{\text {Stark }}(\mathrm{nm})\right]^{1.46808}
$$

Under these conditions, the resulting experimental line shape can be fitted by a Voigt function (convolution product of a Lorentzian and Gaussian), where the Gaussian contribution (Doppler and instrumental broadenings) is known, and the Lorentzian contribution is deconvoluted from the Voigt profile. Knowing van der Waals broadening, Stark broadening can be deduced and 
$n_{e}$ can be measured. Note that, although each experimental spectrum is averaged over 50 accumulations, the error on electron density has been deduced from the fit quality.

\section{RESULTS AND DISCUSSION}

Recently, the plasma characteristics of MWPJ in distilled water were studied in detail in [21], and the main results revealed that gas composition and flow rate strongly affect plasma dynamics and the degradation of MB. In this study, the influence of $\sigma_{\mathrm{w}}$ on various plasma properties and plasma-bubble dynamics was investigated. Note that the dissipation of microwave power in water is not considered here. Section 3.1 presents the optical diagnostics of MWPJ and the main plasma characteristics, such as the rotational temperature of $\mathrm{OH}$ radicals and electron density, as a function of $\sigma_{\mathrm{w}}$. The influence of $\sigma_{\mathrm{w}}$ on plasma-bubble dynamics is presented in Section 3.2, whereas the influence of adding nitrogen is presented in Section 3.3. Finally, in Section 3.4, the influence of $\sigma_{\mathrm{w}}$ on the degradation of MB is discussed.

\subsection{Effect of water electrical conductivity on MWPJ characteristics}

To investigate the plasma characteristics, namely reactive species composition, temperature, and electron density, of the submerged MWPJ, a detailed analysis of the optical emission spectra, under various $\sigma_{\mathrm{w}}$, was performed. Plasma-emitted light was collected near the inlet of the liquid cell using an optical fiber and analyzed with the spectrometer. The spectra presented in Figures $3 \mathrm{a}$ and $3 \mathrm{~b}$ were acquired for various $\sigma_{\mathrm{w}}$ values, at Ar flow rates of $2 \mathrm{~L} / \mathrm{min}$ and $0.6 \mathrm{~L} / \mathrm{min}$, respectively. In all measured spectra, the $\mathrm{OH}(\mathrm{A}-\mathrm{X})$ band and the atomic Ar lines exhibit high intensity. $\mathrm{H}(\alpha, \beta$, and $\gamma), \mathrm{O}$, and $\mathrm{NH}(\mathrm{A}-\mathrm{X})$ lines are also identified. The intensities

of these lines are relatively low compared to those of $\mathrm{OH}$ and Ar. Note that $\mathrm{NH}$ emission at 336 $\mathrm{nm}$ is due to an impurity in Ar and/or to dissolved air in water. The spectral lines at 766 and 769 $\mathrm{nm}$ correspond to emissions of potassium $(\mathrm{K})$ atoms in $\mathrm{KCl}$, and they are visible only at higher $\sigma \mathrm{w}$. 

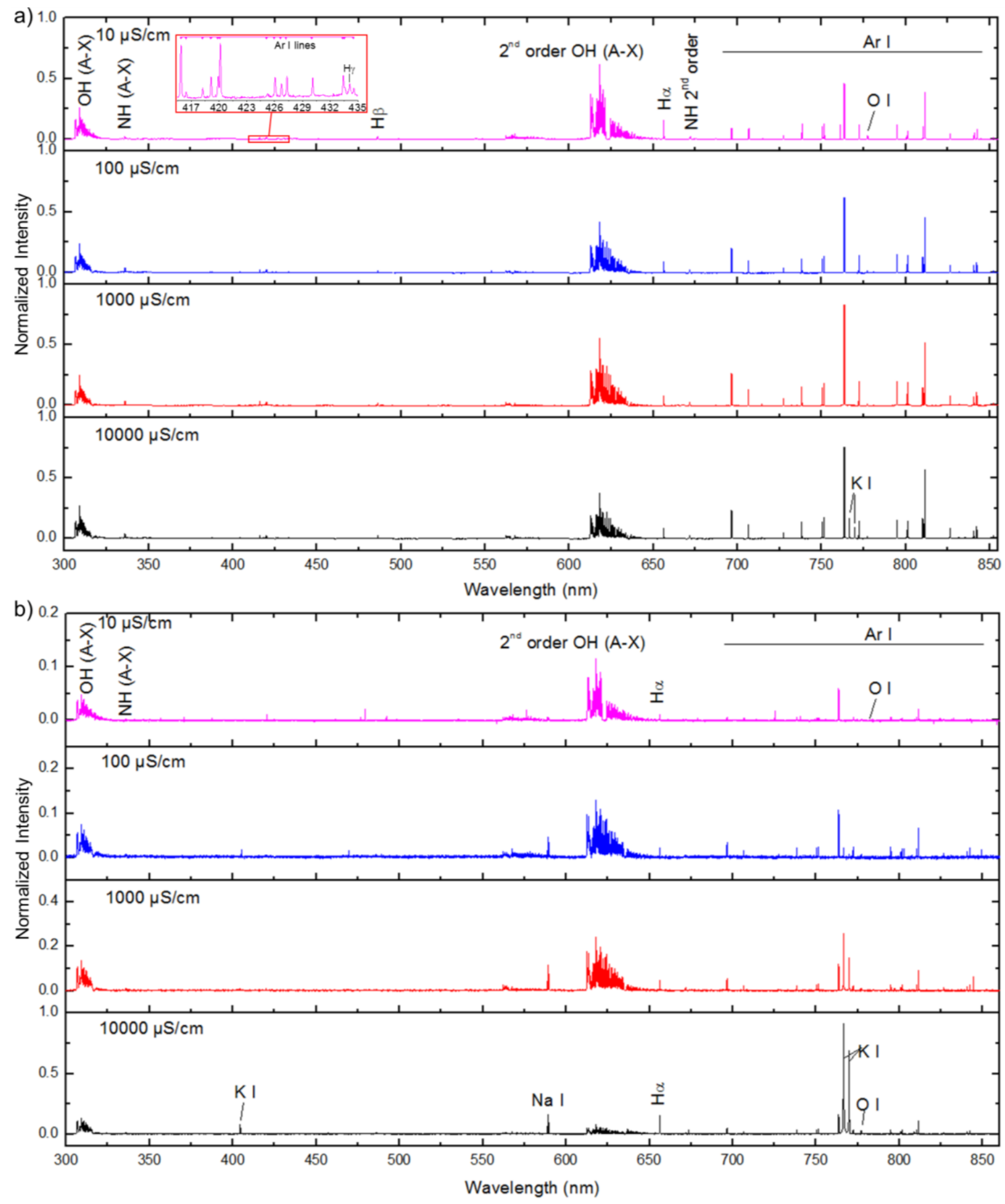

Figure 3. Optical emission spectra acquired at the inlet of the liquid cell for four $\sigma_{w}$ values (10, $100,1000$, and $10000 \mu \mathrm{S} / \mathrm{cm}$ ) at Ar flow rates of a) $2 \mathrm{~L} / \mathrm{min}$ and $\boldsymbol{b}) 0.6 \mathrm{~L} / \mathrm{min} . P=200 \mathrm{~W}$, exposure time $=1 \mathrm{~ms}$, and number of accumulations $=50$. 
All the previously mentioned species were identified at low Ar flow rate $(0.6 \mathrm{~L} / \mathrm{min})$ and low conductivity $\left(\sigma_{\mathrm{w}}=10 \mu \mathrm{S} / \mathrm{cm}\right.$ ) (Figure 3b), albeit at lower band intensities than those observed at the higher flow rate. For $\sigma_{\mathrm{w}} \geq 100 \mu \mathrm{S} / \mathrm{cm}, \mathrm{K}$ and $\mathrm{Na}$ lines are clearly visible in the spectra. Although it is known that $\mathrm{K}$ originates from $\mathrm{KCl}$, $\mathrm{Na}$ may be present as impurity in $\mathrm{KCl}$ salt. The intensities of $\mathrm{K}$ and $\mathrm{Na}$ increase with increasing $\sigma_{\mathrm{w}}$. Note that at $\sigma_{\mathrm{w}}=10000 \mu \mathrm{S} / \mathrm{cm}$, the spectrum is clearly dominated by $\mathrm{K}$ lines.

The data presented so far confirms that the MWPJ effectively dissociates water molecules to produce $\mathrm{OH}$ radicals together with $\mathrm{H}$ and $\mathrm{O}$ radicals; via a mechanism detailed in [27]. As strongly oxidative species, $\mathrm{OH}$ radicals are highly efficient in degrading water-bound organic molecules, and are thus, of great importance for the purpose of water treatment. The recombination of these radicals leads to the production of hydrogen peroxide, $\mathrm{H}_{2} \mathrm{O}_{2}\left(\mathrm{OH}+\mathrm{OH} \rightarrow \mathrm{H}_{2} \mathrm{O}_{2}\right)$, an important agent in the chemical reactivity of plasmas in and in-contact with water [27]. The production rate of $\mathrm{OH}$ radicals is augmented with increased Ar flow rates, as evidenced by its relative intensity (this observation is valid for flow rates up to at least $5 \mathrm{~L} / \mathrm{min}$ ) and results in an increase in $\mathrm{H}_{2} \mathrm{O}_{2}$ concentration in water.

Variations in major emission intensities for $\mathrm{OH}, \mathrm{O}, \mathrm{H}, \mathrm{Ar}$, and $\mathrm{K}$ species as a function of $\sigma_{\mathrm{w}}$, at Ar fow rates of 2 and $0.6 \mathrm{~L} / \mathrm{min}$, are depicted in Figure 4 . The results indicate that as $\sigma_{\mathrm{w}}$ increases from 10 to $1000 \mu \mathrm{S} / \mathrm{cm}$, the intensity of the Ar line increases monotonically. Further increase of $\sigma_{\mathrm{w}}$ to $10000 \mu \mathrm{S} / \mathrm{cm}$ results in a slight decrease of the Ar emission intensity. Although this trend is evident for both Ar flow rates, the measured intensities at $2 \mathrm{~L} / \mathrm{min}$ are two orders of magnitude higher than those measured at $0.6 \mathrm{~L} / \mathrm{min}$ (note that the acquisition parameters were kept the same in both cases). The spectroscopic band intensities of $\mathrm{OH}, \mathrm{H}$, and $\mathrm{O}$ radicals also depend on $\sigma_{\mathrm{w}}$. At $2 \mathrm{~L} / \mathrm{min}$, the variation of $\mathrm{OH}$ intensity as a function of $\sigma_{\mathrm{w}}$ is not significant, whereas the band intensities of $\mathrm{H}$ and $\mathrm{O}$ show a slight decrease as $\sigma_{\mathrm{w}}$ increases from 10 to $100 \mu \mathrm{S} / \mathrm{cm}$, an effect that is not manifested at higher $\sigma_{\mathrm{w}}$. Meanwhile, at Ar flow rate of $0.6 \mathrm{~L} / \mathrm{min}$, emission intensities of $\mathrm{OH}, \mathrm{H}$, and $\mathrm{O}$ radicals are significantly dependent on $\sigma_{\mathrm{w}} \mathrm{H}$ and $\mathrm{O}$ emissions continuously increase with increasing $\sigma_{\mathrm{w}}$, within the tested range, while $\mathrm{OH}$ emission shows somewhat saturated behavior when $\sigma_{\mathrm{w}}$ is increased from 1000 to $10000 \mu \mathrm{S} / \mathrm{cm}$. Note that, at $2 \mathrm{~L} / \mathrm{min}, \mathrm{K}$ emission is observed only at $\sigma_{\mathrm{w}}=10000 \mu \mathrm{S} / \mathrm{cm}$, while, at $0.6 \mathrm{~L} / \mathrm{min}$, it is detectable for $\sigma_{\mathrm{w}} \geq 100 \mu \mathrm{S} / \mathrm{cm}$ demonstrating increasing emission intensity with increased $\sigma_{\mathrm{w}}$. 

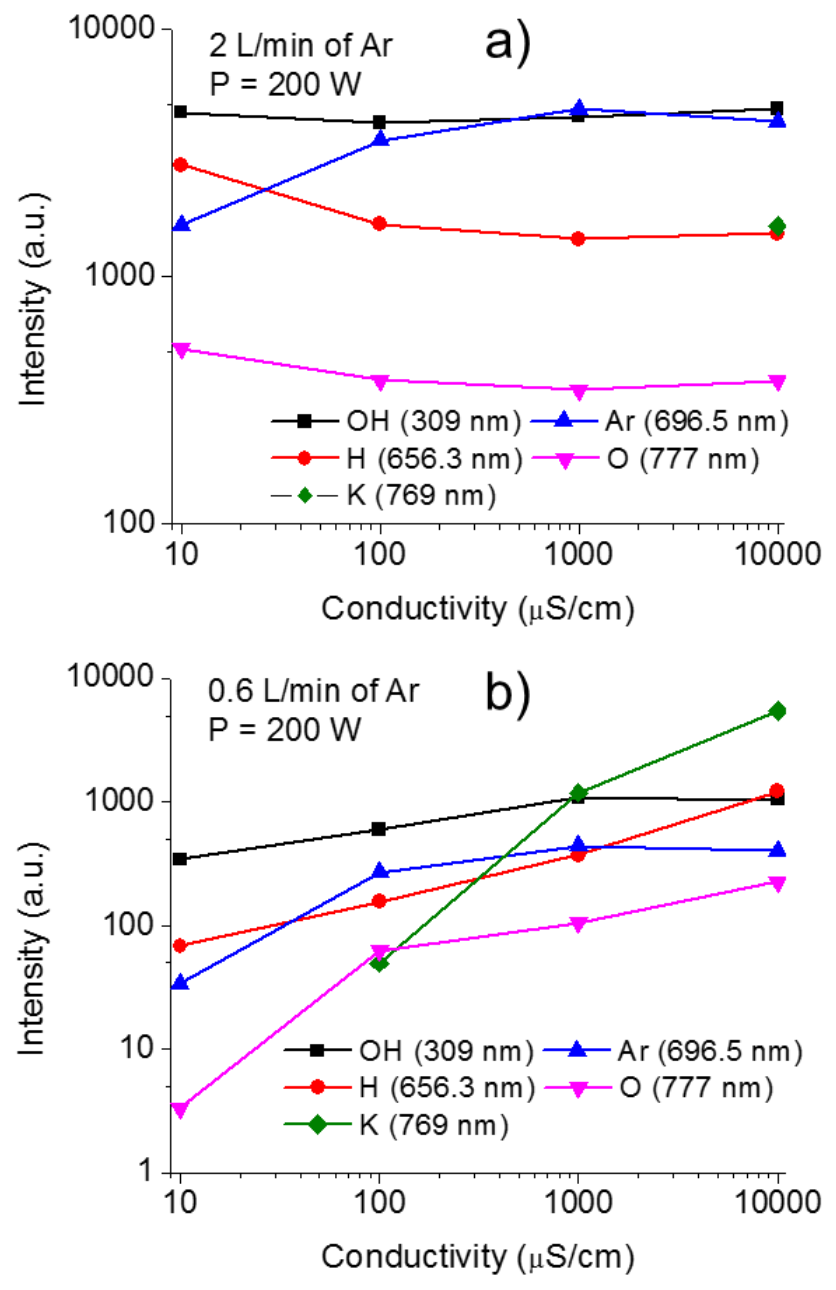

Figure 4. Intensity variations of $\mathrm{OH}(309 \mathrm{~nm}), \mathrm{Ar}(696.5 \mathrm{~nm}), \mathrm{H}(656.3 \mathrm{~nm}), O(777 \mathrm{~nm})$, and $\mathrm{K}(769.8$ $\mathrm{nm})$ spectroscopic bands as a function of $\sigma_{\mathrm{w}}$ for Ar flow rates of a) $2 \mathrm{~L} / \mathrm{min}$ and $\left.\boldsymbol{b}\right) 0.6 \mathrm{~L} / \mathrm{min} . P=200 \mathrm{~W}$ and water volume $=200 \mathrm{~mL}$.

The results obtained in this study show that the spectroscopic band intensities of plasma species in submerged MWPJ are dependent on $\sigma_{\mathrm{w}}$. Such dependency has also been reported by Bruggeman et al. [12] who studied the emission intensities of plasma species in DC-excited discharge in water for $\sigma_{w}$ between 1 and $700 \mu \mathrm{S} / \mathrm{cm}$. Our results show that the investigated band intensities depend on the gaseous flow rate, and, interestingly, the trend reported in [12] (without gas) is similar to what we found at Ar flow rate of $2 \mathrm{~L} / \mathrm{min}$. However, at lower Ar flow rate, we observed a different trend (i.e., continuous increase) suggesting that our MWPJ plasma is very sensitive to both parameters, flow rate and water conductivity.

In fact, Ar flow rate is a very important parameter that can influence species concentrations, as it defines the environment in which the plasma is injected. Evidently, high Ar flow rate produces 
a larger bubble, and vice versa. There is a specificity related to a surfatron device, and more generally to devices using electromagnetic surface wave plasma devices, that is the absorption of the microwave power requires a plasma (a critical electron density) to be developed Therefore, high Ar flow rate will produce a larger bubble in which a longer plasma can be sustained; this has been previously confirmed by a high-speed imaging [21]. In this context, the plasma composition as well as the concentration of various species are closely related to Ar flow rate.

The electrical conductivity dependence of major plasma properties, such as rotational temperature and electron density, was also investigated using optical spectroscopy. The variation of $T_{\text {rot }}$ as a function of $\sigma_{\mathrm{w}}$, for the two typical flow rates ( 2 and $0.6 \mathrm{~L} / \mathrm{min}$ ), is presented in Figure 5Figure 5. The results show that at higher flow rate, $T_{\text {rot }}$ values are relatively lower than those measured at lower flow rate. Figure 5 also shows that $T_{\text {rot }}$ decreases with increasing $\sigma_{\mathrm{w}}$ in the range of $10-100 \mu \mathrm{S} / \mathrm{cm}$, by values of $\sim 500 \mathrm{~K}$ and $\sim 85 \mathrm{~K}$ at $2 \mathrm{~L} / \mathrm{min}$ and $0.6 \mathrm{~L} / \mathrm{min}$, respectively. Further escalation in $\sigma_{\mathrm{w}}$ (up to $10000 \mu \mathrm{S} / \mathrm{cm}$ ) augments $T_{\text {rot }}$ from $\sim 2245 \mathrm{~K}$ to $2640 \mathrm{~K}$ at $2 \mathrm{~L} / \mathrm{min}$, and from $\sim 3030 \mathrm{~K}$ to $3500 \mathrm{~K}$ at $0.6 \mathrm{~L} / \mathrm{min}$. Conversely, the $\sigma_{\mathrm{w}}$-dependence of the $\mathrm{OH}$ rotational temperature was found to be less significant $(\sim 3000 \pm 500 \mathrm{~K})$ in the case of DC-excited discharge in water [12]. This can be related to the investigated range of conductivity. Indeed, our temperatures obtained in the range of 10-1000 $\mu \mathrm{S} / \mathrm{cm}$ show a good agreement with [12], but further increase in $\sigma_{\mathrm{w}}$ to $10000 \mu \mathrm{S} / \mathrm{cm}$ leads to an increase of $\mathrm{OH}$ rotational temperature, probably due to a change in plasma composition that modify the production mechanisms of $\mathrm{OH}(\mathrm{A})$ as well as its deexcitation mechanisms towards $\mathrm{OH}(\mathrm{X})$ state.

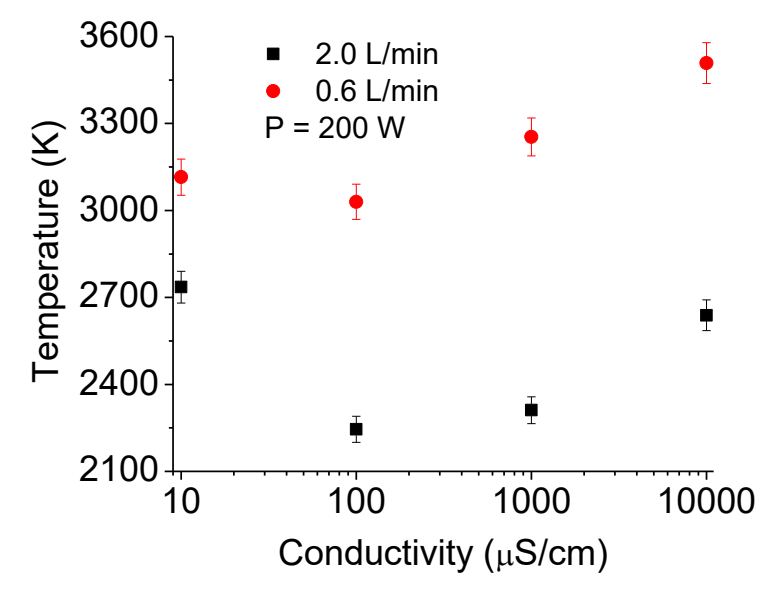

Figure 5. Variation of $\mathrm{OH}$ rotational temperature as a function of $\sigma_{w}$ for two Ar flow rates; $P=200 \mathrm{~W}$ and water volume $=200 \mathrm{~mL}$. 
Figure a depicts the Voigt function fit of a typical $\mathrm{H} \beta$ line profile determined at Ar flow rate $=2 \mathrm{~L} / \mathrm{min}$ and $\sigma_{\mathrm{w}}=10 \mu \mathrm{S} / \mathrm{cm}$, whereas Figure $6 \mathrm{~b}$ presents the variation of measured $n_{e}$ values as a function of $\sigma_{\mathrm{w}}$. Regretfully, it was not possible to estimate $n_{e}$ at low Ar flow rate, due to relatively weak line intensities. The plotted data show a slight decrease of $n_{e}$, from $\sim 6.7 \times 10_{14}$ $\mathrm{cm}^{-} 3$ to $\sim 5.5 \times 1014 \mathrm{~cm}^{-} 3$, as $\sigma_{\mathrm{w}}$ increases from 10 to $10000 \mu \mathrm{S} / \mathrm{cm}$. In the case of DC-excited discharge in water [12], a similar observation was reported, with $n$ e values decreasing from $\sim 10 \times$ $1014 \mathrm{~cm}^{-} 3$ to $\sim 3.0 \times 1014 \mathrm{~cm}^{-} 3$ as $\sigma_{\mathrm{w}}$ increases from 1 to $700 \mu \mathrm{S} / \mathrm{cm}$. The relatively high values reported at low conductivity and relatively low values reported at high conductivity can be related to a variation in plasma-bubble dynamic. Indeed, at low conductivity the discharge is about a streamer-like in liquid. Such a discharge mode is known to produce high electron density because of the confinement of a plasma channel in liquid. Whereas, at high conductivity, it becomes a plasma in bubble (attached at gas-liquid interface): a mode that has relatively low electron density.
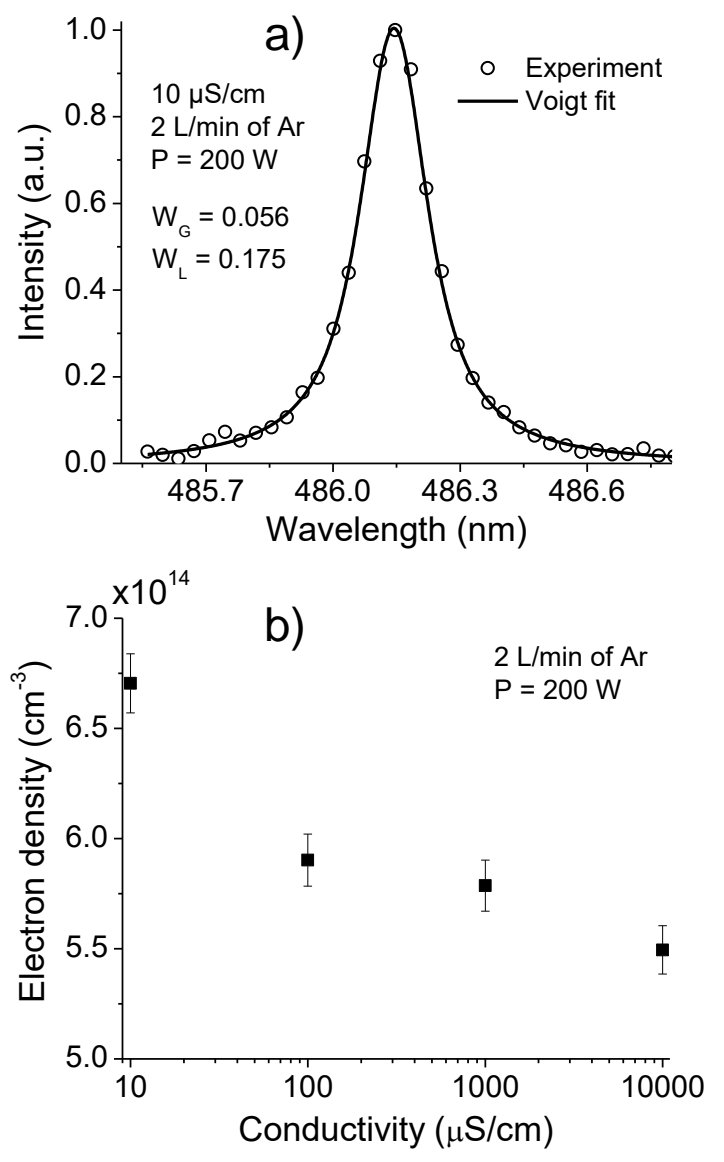

Figure 6. a) Typical experimental and simulated profile of the $H \beta$ line. $\boldsymbol{b})$ Variation of the electron density (ne) as a function of $\sigma_{w} . P=200 \mathrm{~W}$, water volume $=200 \mathrm{~mL}$, and Ar flow rate $=2 \mathrm{~L} / \mathrm{min}$. 


\subsection{The effect of $\sigma_{w}$ on plasma-bubble dynamics}

To better understand the effect of electrical conductivity, spatially and temporally resolved plasma dynamics was investigated at the entry of MWPJ to the liquid cell, under various conditions of Ar flow rate and $\sigma_{\mathrm{w}}$, using high-speed imaging technique. Instantaneous plasma/bubble images were recorded at selected elapsed times, and are depicted in Figure 7Figure . Initial time $(t=0)$ indicates the moment right after the detachment of a previous bubble from the entry of the MWPJ during a periodic cycle. It is worth noting that the residence time of a bubble in water is highly dependent on both gas flow rate and microwave power; however, its dependence on $\sigma_{\mathrm{w}}$ is not significant (typically, at Ar flow rate $=2 \mathrm{~L} / \mathrm{min}$ and $\mathrm{P}=200 \mathrm{~W}$, the residence time is $\sim 400 \mathrm{~ms}$ ). At flow rate $=0.6 \mathrm{~L} / \mathrm{min}$ and $\sigma_{\mathrm{w}}=10$ or $100 \mu \mathrm{S} / \mathrm{cm}$, the plasma does not penetrate the bubble (Figures $7 \mathrm{a}$ and $7 \mathrm{~b}$ ), and the observed dynamics corresponds to that of a gaseous bubble in water. Meanwhile, the images recorded at $\sigma_{\mathrm{w}}=1000 \mu \mathrm{S} / \mathrm{cm}$ (Figure 7c), exhibit a tiny plasma in the bubble. Finally, for $\sigma_{\mathrm{w}}=5000$ and $10000 \mu \mathrm{S} / \mathrm{cm}$ (Figures 7d and 7e), a strong plasma is observed while the bubble is attached to the entry. This indicates a strong influence of water electrical conductivity on the remotely generated MWPJ.

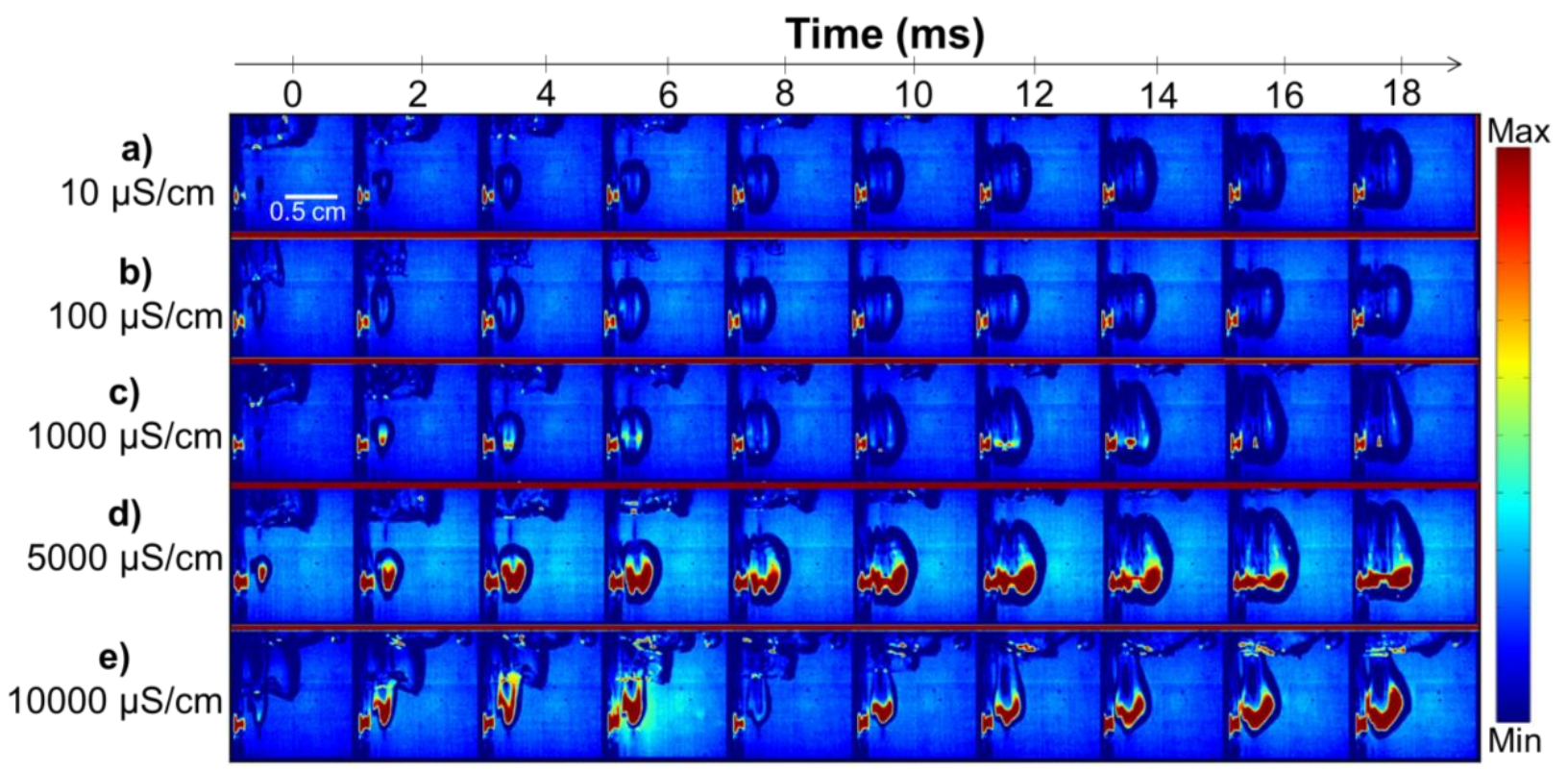

Figure 7. Plasma-bubble dynamics for various $\sigma_{w}$, at Ar flow rate $=0.6 \mathrm{~L} / \mathrm{min}, P=200 \mathrm{~W}$, and water volume $=200 \mathrm{~mL}:$ a) $\sigma_{w}=10 \mu \mathrm{S} / \mathrm{cm}$, b) $\left.\left.\sigma_{w}=100 \mu \mathrm{S} / \mathrm{cm}, \boldsymbol{c}\right) \sigma_{w}=1000 \mu \mathrm{S} / \mathrm{cm}, \boldsymbol{d}\right) \sigma_{w}=5000 \mu \mathrm{S} / \mathrm{cm}$, and e) $\sigma_{w}=10000 \mu \mathrm{S} / \mathrm{cm}$. 
Similarly, Figure Figure 8 shows the time evolution of the plasma-bubble dynamics for various $\sigma_{\mathrm{w}}$, but at an $\mathrm{Ar}$ flow rate of $0.8 \mathrm{~L} / \mathrm{min}$. The results show that the dynamics are not significantly affected by the small increase in Ar flow rate from 0.6 to $0.8 \mathrm{~L} / \mathrm{min}$ when $\sigma_{\mathrm{w}} \leq 1000$ $\mu \mathrm{S} / \mathrm{cm}$. However, at $\sigma_{\mathrm{w}}=5000 \mu \mathrm{S} / \mathrm{cm}$, the strongly inhomogeneous plasma, particularly for $t<6$ ms (see zoom presented as 1 in Figure 8), is likely to fill a larger portion of the bubble volume. Such bubble filling is an important feature as it may increase the plasma-water interaction, thereby enhancing the treatment efficiency. For $t \geq 6 \mathrm{~ms}\left(\sigma_{\mathrm{w}}=5000 \mu \mathrm{S} / \mathrm{cm}\right)$, the plasma becomes asymmetric: decrease in the left-hand side region and increase in the right-hand side region (see zoom presented as 2 and 3 in Figure 8). The superposition of the magnified plasma boundaries measured at 4, 8, and $12 \mathrm{~ms}$ indicates that the ionized volume increases in the direction of the carrier flow (i.e., momentum), as well as towards the surface of the liquid (i.e., buoyancy). Finally, at $\sigma_{\mathrm{w}}=10000 \mu \mathrm{S} / \mathrm{cm}$, the plasma is filamentary-shaped, and is attached to the gas-water interface at the bottom of the bubble. The global plasma volume is relatively smaller than that observed at $\sigma_{\mathrm{w}}=5000 \mu \mathrm{S} / \mathrm{cm}$.

\section{Time (ms)}

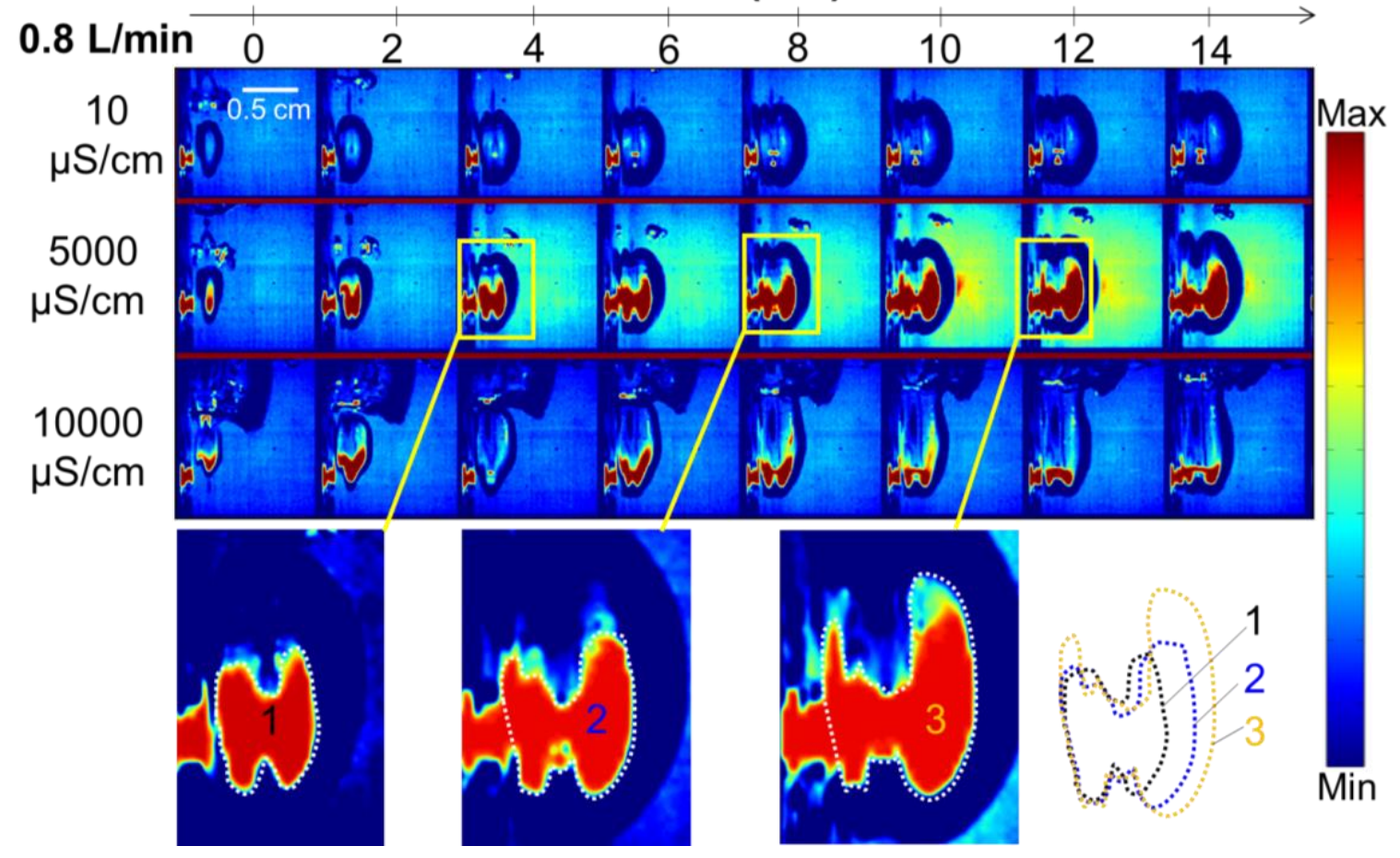

Figure 8. Plasma-bubble dynamics for various $\sigma_{w}$, at Ar flow rate $=0.8 \mathrm{~L} / \mathrm{min}, P=200 \mathrm{~W}$ and water volume $=200 \mathrm{~mL}$. 
Further increase in Ar flow rate to $1 \mathrm{~L} / \mathrm{min}$ induces additional changes in plasma dynamics (Figure 9a). For $\sigma_{\mathrm{w}} \leq 1000 \mu \mathrm{S} / \mathrm{cm}$, filamentary shaped plasma is observed in the bubble starting at $t=0 \mathrm{~ms}$, which indicates improved bubble penetration with increasing gas flow rate. Meanwhile, at $\sigma_{\mathrm{w}}=5000 \mu \mathrm{S} / \mathrm{cm}$, the plasma fills the bubble, with maximum filling rate at $t=10 \mathrm{~ms}$. The asymmetrical shape of the plasma observed at $t \geq 12 \mathrm{~ms}\left(\sigma_{\mathrm{w}}=5000 \mu \mathrm{S} / \mathrm{cm}\right)$ is probably due to the instability (due to momentum and buoyancy) of the bubble interface. Finally, at $\sigma_{\mathrm{w}}=10000 \mu \mathrm{S} / \mathrm{cm}$, the plasma homogeneously fills the bubble for a few milliseconds ( $t \leq 2 \mathrm{~ms})$, before turning into a thin filament, as shown in Figure 9a. The plasma filament is also observed for Ar flow rates $\geq 2$ $\mathrm{L} / \mathrm{min}$ (the tested upper limit is $5 \mathrm{~L} / \mathrm{min}$ ), regardless of the magnitude of electrical conductivity (Figure 9b). Plasma-bubble dynamic is weakly dependent on $\sigma_{\mathrm{w}}$ under such conditions.

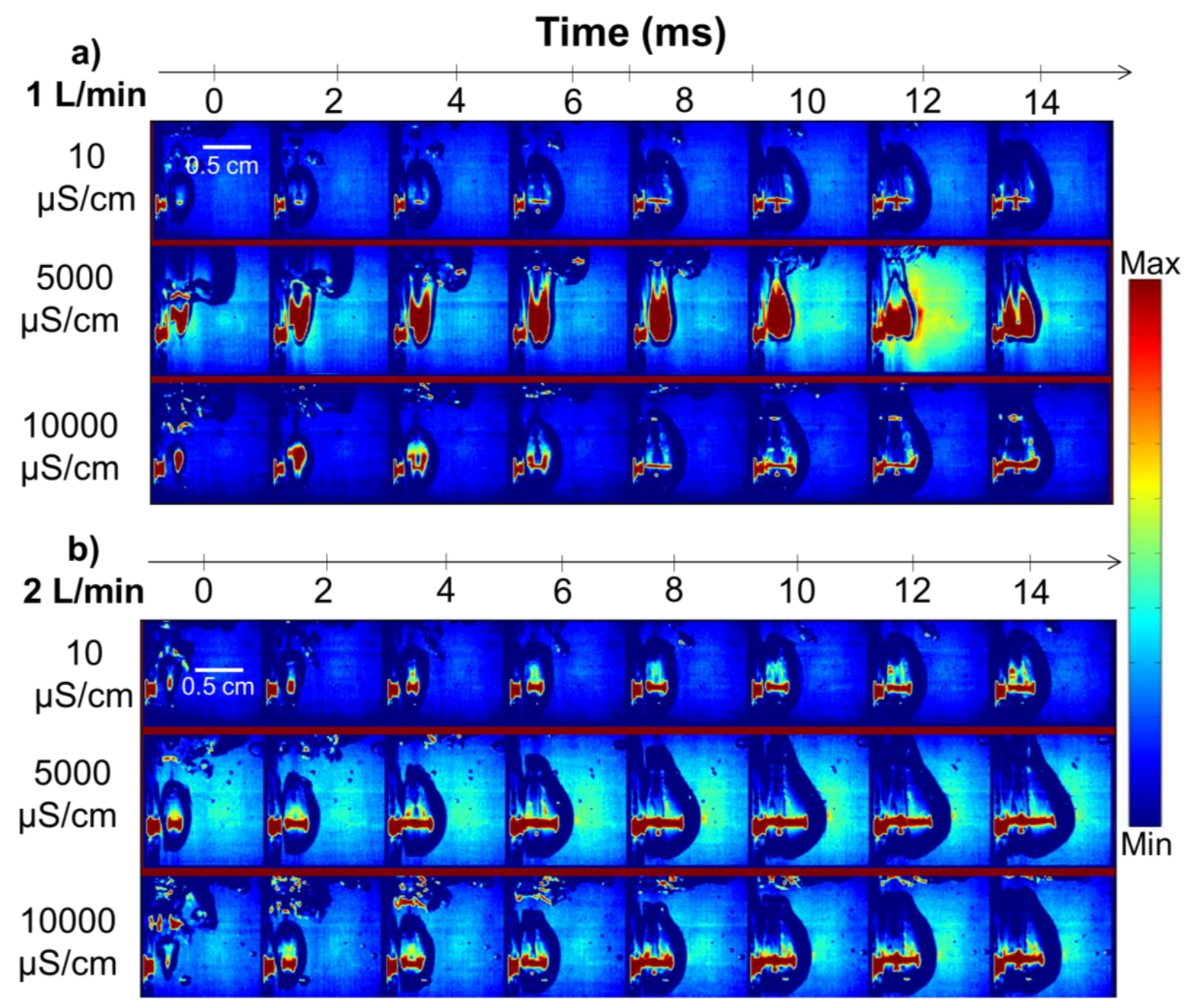

Figure 9. Plasma-bubble dynamics recorded at Ar flow rates of a) $1 \mathrm{~L} / \mathrm{min}$ and $\boldsymbol{b}$ ) $2 \mathrm{~L} / \mathrm{min}$, for various $\sigma_{w}(P=200 \mathrm{~W}$ and water volume $=200 \mathrm{~mL})$. 
The results presented thus far show that the influence of $\sigma_{\mathrm{w}}$ and Ar flow rate on plasma dynamics seems to be coupled. We remark that plasma propagation in the bubble is enhanced upon increasing $\sigma_{\mathrm{w}}$, and that the plasma completely and homogeneously fills the bubble at flow rates lower than $2 \mathrm{~L} / \mathrm{min}$. Maximum plasma volume and intensity were observed for Ar flow rate $=1$ $\mathrm{L} / \mathrm{min}$ and $\sigma_{\mathrm{w}}=5000 \mu \mathrm{S} / \mathrm{cm}$. Both, high-speed images and optical emission data concur that $\sigma_{\mathrm{w}}$ exhibits greater effects on plasma characteristics at lower gaseous flow rates. In fact, increasing $\sigma_{\mathrm{w}}$ is due to increased amount of dissociated $\mathrm{K}_{+}$and $\mathrm{Cl}^{-}$by adding more $\mathrm{KCl}$ in water. Injecting gas into liquid results in a bubble formation that is rich in vapor inside, and the concentration of vapor is dependent on temperature, an interfacial surface area, and a volume of a bubble. At $\sigma_{\mathrm{w}}=$ $10 \mu \mathrm{S} / \mathrm{cm}$, without $\mathrm{KCl}$ addition, the bubble composition should be Ar and water vapor only. As $\sigma_{\mathrm{w}}$ is increased, for a given Ar flow rate, concentrations of $\mathrm{K}_{+}$and $\mathrm{Cl}^{-}$should increase in the bubble. However, for a given $\sigma_{\mathrm{w}}$, increasing Ar flow will produce a larger bubble in which concentration of $\mathrm{K}+$ and $\mathrm{Cl}^{-}$are expected to decrease, since a volume to surface ratio of a bubble $\left(\sim d_{3} / d_{2} \sim d ; d\right.$ is the bubble diameter) is increased as the volume of the bubble increases. When MWPJ is injected into such a liquid medium, its composition is thus significantly influenced by a bubble composition. On the other hand, as the electrons have a mobility three orders of magnitude higher than those of ions, electrons diffuse (radially and axially) towards a gas-liquid interface. Therefore, at high $\sigma_{\mathrm{w}}$, i.e., high concentration of ions due to dissolved $\mathrm{KCl}$, it would be easier for electrons to recombine with $\mathrm{K}+$ to produce $\mathrm{K}$. As $\mathrm{K}$ has low ionization/excitation energies, they can be easily ionized/excited and emits radiation. For a couple Ar flow rate and $\sigma_{\mathrm{w}}$ (for instance: $1 \mathrm{~L} / \mathrm{min}$ and $5000 \mu \mathrm{S} / \mathrm{cm}$ - Figure 9), since $\mathrm{K}_{+}$(and thus $\mathrm{K}$ atoms) should be distributed throughout a volume of the bubble, a light emission can partially or completely fill the gaseous volume. This may explain the various plasma-bubble dynamics.

\subsection{The effect of $N_{2}$ on MWPJ characteristics and plasma dynamics}

Adding $\mathrm{N}_{2}$ to Ar significantly influences plasma properties, including electron density, electron temperature, and gas temperature [28], [29]. Recently, we have shown that the addition of $1-2 \% \mathrm{~N}_{2}$ to the Ar flow in MWPJ improves the efficiency of MB degradation [21]. In this study, we investigate whether such enhancement can be achieved for highly conductive wastewater. 
Specifically, we assess the effect of increasing $\mathrm{N}_{2}$ content on the plasma characteristics of MWPJ and degradation kinetics of $\mathrm{MB}$, under various conditions of $\sigma_{\mathrm{w}}$. Since the emission intensities are too low to allow for confident analysis at lower flow rates, the $\mathrm{N}_{2}$ effect was evaluated only at 2 $\mathrm{L} / \mathrm{min}$. Figures $10 \mathrm{a}$ and $10 \mathrm{~b}$ present variations in spectral line intensities of major species $(\mathrm{OH}, \mathrm{Ar}$, $\mathrm{H}, \mathrm{O}, \mathrm{K}$, and $\mathrm{NH}$ ) as a function of $\mathrm{N}_{2}$ percentage, at $\sigma_{\mathrm{w}}=10000$ and $10 \mu \mathrm{S} / \mathrm{cm}$, respectively. Meanwhile, the effects of $\mathrm{N}_{2}$ addition on $T_{r o t}$ and $n_{e}$ are illustrated in Figures $10 \mathrm{c}$ and 10d, respectively. The spectra acquired at $\sigma_{\mathrm{w}}=10000 \mu \mathrm{S} / \mathrm{cm}$ are presented in supplemental material 1 . For both tested values of electrical conductivity, the $\mathrm{NH}(\mathrm{A}-\mathrm{X})$ emission intensity increases from a non-zero value at $0 \% \mathrm{~N}_{2}$ (signal due impurity and/or dissolved air in water) to a maximum at $0.5 \% \mathrm{~N}_{2}$. The signal intensity subsequently decreases upon further increasing $\mathrm{N}_{2}$ content. At 10000 $\mu \mathrm{S} / \mathrm{cm} \mathrm{NH}$ exhibits the highest signal compared to other lines in the emission spectrum; however, at $10 \mu \mathrm{S} / \mathrm{cm}$, the highest intensity is that of $\mathrm{OH}$. The intensities of $\mathrm{Ar}, \mathrm{OH}$, and $\mathrm{O}$ lines continuously decrease with increasing $\mathrm{N}_{2}$ content at both investigated conditions. For $\sigma_{\mathrm{w}}=10000 \mu \mathrm{S} / \mathrm{cm}$, maximum $\mathrm{H}$ line intensity is observed at $1 \%$ of $\mathrm{N}_{2}$, but it decreases monotonically for $\sigma_{\mathrm{w}}=10$ $\mu \mathrm{S} / \mathrm{cm}$. As for K, its line intensity continuously increases with increasing $\mathrm{N}_{2}$ percentage for $\sigma_{\mathrm{w}}=$ $10000 \mu \mathrm{S} / \mathrm{cm}$. The $\mathrm{K}$ signal is absent in the spectrum recorded for the $10 \mu \mathrm{S} / \mathrm{cm}$ sample since no $\mathrm{KCl}$ was added. Finally, nitrogen lines, namely $\mathrm{N}_{2}$ and $\mathrm{N}_{2+}$, are observed, but their data are not shown due to relatively low intensities compared to the other lines. This observation indicates that, except for $\mathrm{K}$, all signals decline upon the addition of $\mathrm{N}_{2}$, regardless of $\sigma_{\mathrm{w}}$. 

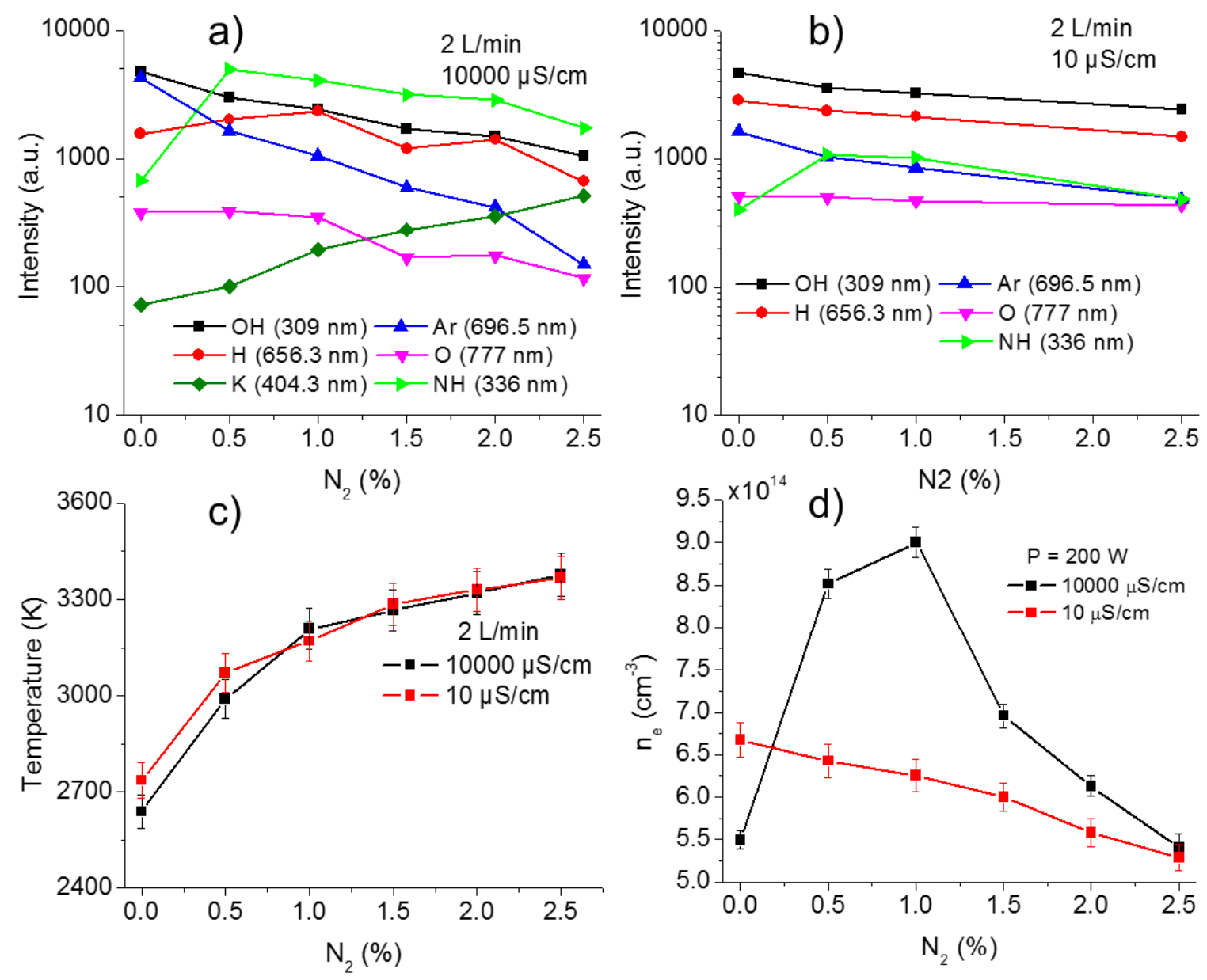

Figure 10. Emission intensity variations of $\mathrm{OH}(309 \mathrm{~nm}), \operatorname{Ar}(696.5 \mathrm{~nm}), \mathrm{H}(656.3 \mathrm{~nm}), O(777 \mathrm{~nm})$, and $K(769.8 \mathrm{~nm})$ as a function of $\mathrm{N}_{2}$ percentage for water samples with electrical conductivities of 10000 $\mu \mathrm{S} / \mathrm{cm}(\boldsymbol{a})$ and $10 \mu \mathrm{S} / \mathrm{cm}$ (b) (spectra recorded at Ar- $N_{2}$ flow rate of $2 \mathrm{~L} / \mathrm{min}$ ). Variations of rotational temperature $(\boldsymbol{c})$ and electron density $(\boldsymbol{d})$ variation as a function of $\mathrm{N}_{2}$ percentage in $\mathrm{Ar} . P=200 \mathrm{~W}$, water volume $=200 \mathrm{~mL}$.

Figure 10c shows that, regardless of water conductivity, $T_{\text {rot }}$ continuously increases from $\sim 2700 \mathrm{~K}$ to $\sim 3400 \mathrm{~K}$ as $\mathrm{N}_{2}$ content increases from 0 to $2.5 \%$. Previous studies have shown that such increase in temperature is due to the excitation of $\mathrm{N}_{2}$ rotational levels, with contributions from other phenomena such as excitation of vibrational and electronic levels, ionization, and dissociation [25], [28], [29]. Although this explanation is very well accepted for gas-phase microwave plasmas, our results show that it is also valid for the submerged MWPJ investigated in this study.

The variation of $n_{e}$ as a function of $\mathrm{N}_{2}$ percentage is presented in Figure 10d. The illustrated results indicate that at $\sigma_{\mathrm{w}}=10 \mu \mathrm{S} / \mathrm{cm}, n_{e}$ slightly decreases from $\sim 6.7 \times 1014 \mathrm{~cm}^{-} 3$ to 
$\sim 5.2 \times 1014 \mathrm{~cm}^{-} 3$ as $\mathrm{N}_{2}$ percentage increases from 0 to $2.5 \%$. However, at $\sigma_{\mathrm{w}}=10000 \mu \mathrm{S} / \mathrm{cm}, n_{e}$ reaches a maximum of $\sim 9 \times 1014 \mathrm{~cm}^{-} 3$ at $1 \% \mathrm{~N}_{2}$, then continuously decreases down to $\sim 5.2 \times 1014$ $\mathrm{cm}^{-} 3$ at $2.5 \% \mathrm{~N}_{2}$. Previously, the influence of $\mathrm{N}_{2}$ addition (up to 10\%) on the properties of $\mathrm{Ar}$ surface-wave atmospheric-pressure plasmas was extensively investigated, both, experimentally and theoretically. The results reported a similar increase in temperature and decrease in $n_{e}$ upon increasing $\mathrm{N}_{2}$ content. For instance, Bravo et al. [28] show that increasing $\mathrm{N}_{2}$ percentage from 0 to $10 \%$ results in a drop of $n_{e}$ by one order of magnitude (from $\sim 1014$ to $1013 \mathrm{~cm}^{-} 3$ ). In fact, the addition of $\mathrm{N}_{2}$ to Ar, even at very low percentages ( $\left.<1 \%\right)$, leads to power loss due to molecular excitation/ionization phenomena that undermine the ionization of Ar and generation of electrons. The results obtained herein for $\sigma_{w}=10 \mu \mathrm{S} / \mathrm{cm}$ agree with those observed in previous studies; however, at $\sigma_{w}=10000 \mu \mathrm{S} / \mathrm{cm}$, discrepancies are detected. Thus, further investigation is needed to discern the underlying plasma physics and chemistry of MWPJ at high $\sigma_{\mathrm{w}}$.

The effect of $\mathrm{N}_{2}$ on plasma-bubble dynamics is investigated using the high-speed imaging technique. Figure 11 depicts the plasma emission images for experiments run at various conditions of $\mathrm{N}_{2}$ percentage and $\sigma_{\mathrm{w}}$ (flow rate $=2 \mathrm{~L} / \mathrm{min}$ ); all the presented images correspond to $t=18 \mathrm{~ms}$. The results show that at $\sigma_{\mathrm{w}}=10 \mu \mathrm{S} / \mathrm{cm}$, plasma length decreases with increasing $\mathrm{N}_{2}$ content between 0 and $5 \%$. At $5 \% \mathrm{~N}_{2}$, no plasma channel is perceived in the bubble, but a tiny plasma close to the inlet can be observed. Appreciable effects of $\sigma_{\mathrm{w}}$ on plasma dynamics are detected at $\mathrm{N}_{2}$ percentages $\geq 2 \%$ wherein the plasma channel becomes thicker and longer with increasing conductivity. This indicates that discharge channel (represented by the emission intensity in Figure 11) deterioration due to increased $\mathrm{N}_{2}$ content can be compensated by increasing the conductivity of water. However, this does not signify greater efficiency for water treatment, since the process depends on chemical and physical phenomena other the photon emission. 


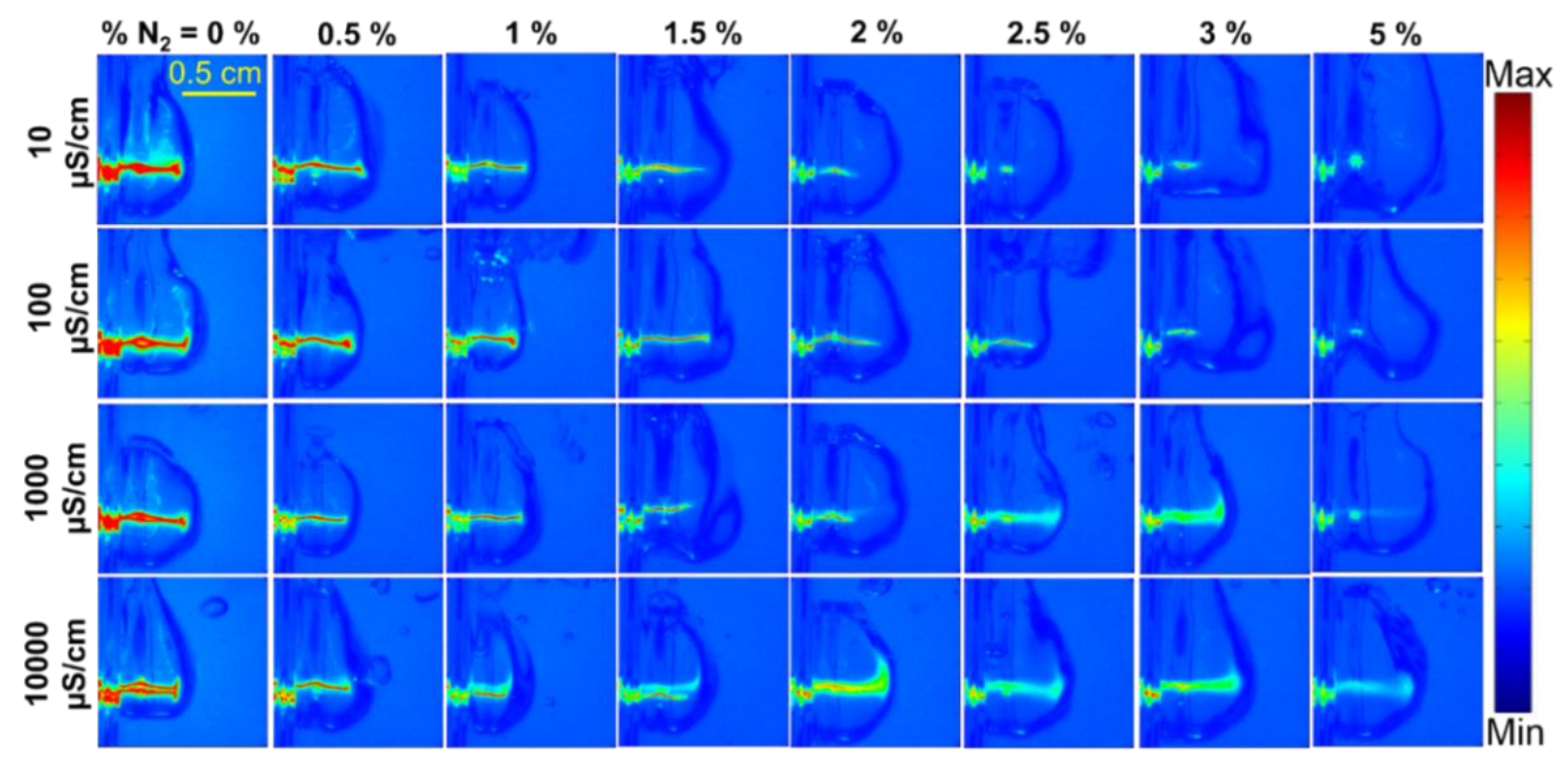

Figure 11. Plasma-bubble dynamics at $t=18 \mathrm{~ms}$ for varying conditions of $\sigma_{w}$ and $N_{2}$ percentage. Flow rate $=2 \mathrm{~L} / \mathrm{min}, P=200 \mathrm{~W}$, and water volume $=200 \mathrm{~mL}$.

\subsection{Methylene blue degradation as a function of $\sigma_{\mathrm{w}}$}

As previously mentioned, our goal is to investigate whether the MWPJ can be a feasible candidate for a wastewater treatment, especially a degradation of organic pollutants presented in water. In a recent study, we had shown that the addition of $1-2 \% \mathrm{~N}_{2}$ to Ar promotes the degradation of MB in distilled water by the MWPJ [21]. Meanwhile, wastewater has a wide range of electrical conductivity (e.g., up to $30 \mathrm{mS} / \mathrm{cm}$ for ballast water [4]), and the degradation of pollutants by plasma under such high conductivity conditions is not investigated. Moreover, the efficiency of direct electrical discharges in water is highly reduced as water conductivity is augmented [14], [16]. In this regard, to maintain a generation of a plasma in a conductive media, advanced technology is usually needed, e.g., high-voltage source with very fast rising time [14], although electrode erosion is always manifesting once it is in contact with plasma. Very recently, a MWPJ in TIAGO (Torche à Injection Axiale sur Guide d'Onde, in French) configuration has been studied and it shows very high potential to remove organic pollutants from water at high conductivity [30].

Here, to highlight the combined influence of $\sigma_{\mathrm{w}}$ and $\mathrm{N}_{2}$ on MB degradation efficiency, experiments were run at the same conditions as in [21] (microwave power of $200 \mathrm{~W}$, treated water volume of $200 \mathrm{~mL}$, and total processing time of $10 \mathrm{~min}$ ), for varying conditions of electrical conductivity and $\mathrm{N}_{2}$ percentage. Figure 12 presents the variation of normalized absorbance 
intensities at $663 \mathrm{~nm}$ as a function of $\sigma_{\mathrm{w}}$ and compares the profiles obtained at different conditions of $\mathrm{N}_{2}$ added and flow rate. At $2 \mathrm{~L} / \mathrm{min}$ of pure Ar, normalized MB absorbance values decrease from $\sim 0.82$ to $\sim 0.55$ as $\sigma_{\mathrm{w}}$ increases from 10 to $100 \mu \mathrm{S} / \mathrm{cm}$; however, further increase in $\sigma_{\mathrm{w}}$ (up to $10000 \mu \mathrm{S} / \mathrm{cm}$ ) does not significantly influence the degradation of MB. These results indicate that MB degradation is significantly enhanced as $\sigma_{\mathrm{w}}$ increases from 10 to $100 \mu \mathrm{S} / \mathrm{cm}$. Previously shown physical characteristics of the MWPJ ( $n$ e, temperature, and plasma-bubble dynamics) do not show any significant changes, showing only Ar intensity is significantly increased (Ar intensity shows a similar trend to MB removal rate). Although a relationship between Ar (including those in metastable states) and $\mathrm{MB}$ degradation rate cannot be readily provided, we believe that the production of reactive species is enhanced as the conductivity is increased from 10 to $100 \mu \mathrm{S} / \mathrm{cm}$. Further increase in conductivity does not show further improvement in the degradation rate.

The incorporation of $1 \% \mathrm{~N}_{2}$ into the gaseous flow (both flows are tested $2 \mathrm{~L} / \mathrm{min}$ and 1 $\mathrm{L} / \mathrm{min}$ ) slightly enhances the degradation efficiency for $\sigma_{\mathrm{w}}=10 \mu \mathrm{S} / \mathrm{cm}$, which has been already observed in [21]. However, as $\sigma_{\mathrm{w}}$ increases from 100 to $10000 \mu \mathrm{S} / \mathrm{cm}, \mathrm{MB}$ absorbance increases linearly from 0.88 to 0.97 , indicating a decline in $\mathrm{MB}$ degradation efficiency. This means that adding a few percent of $\mathrm{N}_{2}$ in Ar enhances MB degradation in water at very low conductivity, but not that effective at higher conductivities. To deeply investigate the fundamental mechanisms of these results, a model development is needed.

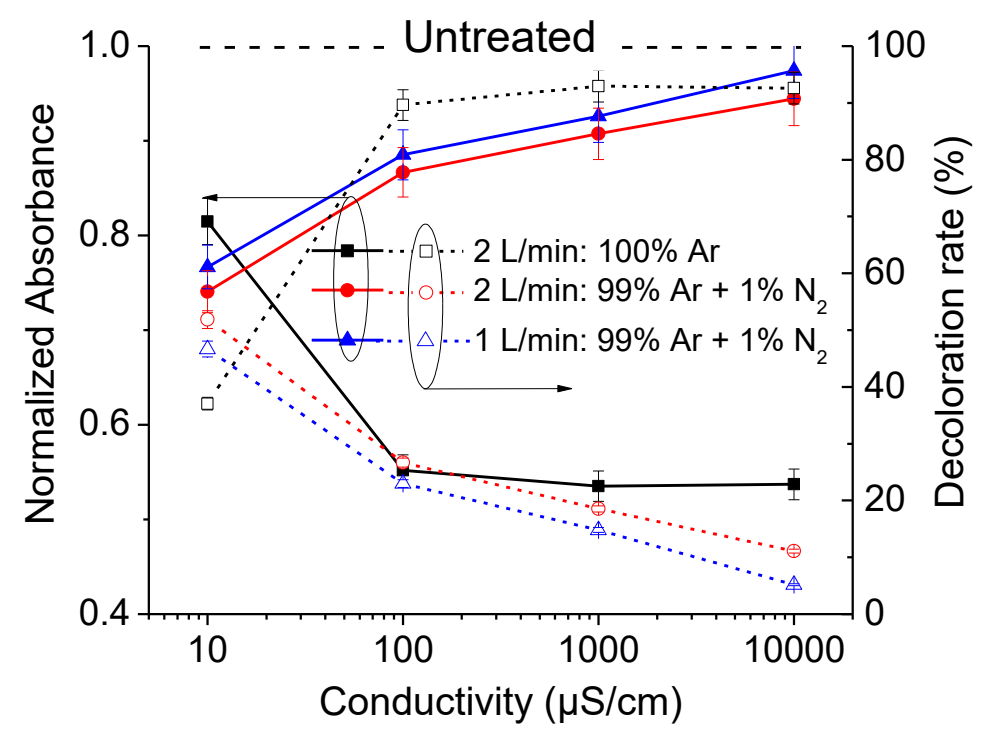

Figure 12. Variation of normalized $M B$ absorbance as a function of $\sigma_{w}$ for varying conditions of $\% \mathrm{~N}_{2}$ added and flow rate. 
Compared to distilled water [21], the increased electrical conductivity of water seems to have a negative effect on the degradation of MB, even with the addition of N2. Meanwhile, highspeed images show that the increased conductivity has a positive impact on the emission volume of the plasma channel (Figures 7, 8, 9, and 11). Spectroscopic analyses indicate that K emission lines dominate upon the augmentation of conductivity (Figure 4) due to increased amounts of dissociated $\mathrm{KCl}$, as well as the low ionization/excitation energy of $\mathrm{K}$. In solution, $\mathrm{KCl}$ breaks up into $\mathrm{K}_{+}$and $\mathrm{Cl}^{-}$. $\mathrm{K}+$ captures plasma electrons to give $\mathrm{K}$ atoms. Conductivity is increased upon augmenting the quantity of added $\mathrm{KCl}$, which results in higher concentrations of $\mathrm{K}+$ and ultimately leads to greater amounts of $\mathrm{K}$, as well as lower electron densities. However, $\mathrm{K}$ is not a reactive species, and thus, it cannot contribute to MB degradation. Therefore, when the amount of $\mathrm{K}$ in solution is high, the degradation efficiency of MB is relatively low. Although, these statements can explain the obtained results, the characterization of the liquid phase, by measuring the concentration of various reactive species under various experimental conditions, is highly recommended.

\section{CONCLUSION}

In this study, the effect of the electrical conductivity of water $\left(\sigma_{\mathrm{w}}\right)$ on plasma characteristics of MWPJ is investigated using optical emission spectroscopy. Variations of $\sigma_{\mathrm{w}}$ between 10 and $10000 \mu \mathrm{S} / \mathrm{cm}$ are achieved by manipulating the amount of $\mathrm{KCl}$ added to distilled water. The obtained results show that at high Ar flow rates (typically $\geq 2 \mathrm{~L} / \mathrm{min}$ ), the plasma composition does not significantly depend on $\sigma_{\mathrm{w}}$, but the intensities of $\mathrm{OH}, \mathrm{H}, \mathrm{O}$, and Ar emission lines do. Moreover, as electrical conductivity increases, $n_{e}$ decreases. Meanwhile, $T_{r o t}$ decreases with increasing $\sigma_{\mathrm{w}}$ between 10 to $100 \mu \mathrm{S} / \mathrm{cm}$, then it continuously increases as $\sigma_{\mathrm{w}}$ is augmented to $10000 \mu \mathrm{S} / \mathrm{cm}$.

High-speed images show that at low $\sigma_{\mathrm{w}}$ and Ar flow rates $<2 \mathrm{~L} / \mathrm{min}$ the plasma is a thin ionized channel in the bubble. As $\sigma_{\mathrm{w}}$ is augmented, the plasma tends to fill the whole bubble volume, with maximum filling at $\sigma_{\mathrm{w}}=5000 \mu \mathrm{S} / \mathrm{cm}$ and Ar flow rate $=1 \mathrm{~L} / \mathrm{min}$. At low $\sigma_{\mathrm{w}}$, the addition of $\mathrm{N}_{2}$ to the gaseous flow decreases plasma length (and intensity), eventually leading to its extinction at $\mathrm{N}_{2} \%>5 \%$. As $\sigma_{\mathrm{w}}$ increases, the plasma can be sustained in the bubble for higher $\mathrm{N}_{2}$ percentage. 
Finally, the influence of $\sigma_{\mathrm{w}}$ on water treatment efficiency is tested by analyzing the degradation rates of MB. The results indicate that the investigated MWPJ becomes less efficient in removing $\mathrm{MB}$ as $\sigma_{\mathrm{w}}$ increases, even with the addition of $\mathrm{N}_{2}$. This may be due to the loss of electrons via electron-ion (here $\mathrm{K}_{+}$) recombination, followed by power loss through excitation/ionization of low-energy species (here $\mathrm{K}$ ). These findings are of great importance for plasma-induced wastewater treatment applications, as the electrical conductivity of polluted water varies within a wide range. 


\section{REFERENCES}

[1] T. Belmonte, A. Hamdan, F. Kosior, C. Noël, and G. Henrion, "Interaction of discharges with electrode surfaces in dielectric liquids: Application to nanoparticle synthesis," $J$. Phys. D. Appl. Phys., vol. 47, no. 22, 2014.

[2] A. Hamdan, C. Noël, J. Ghanbaja, and T. Belmonte, "Comparison of aluminium nanostructures created by discharges in various dielectric liquids," Plasma Chem. Plasma Process., vol. 34, no. 5, pp. 1101-1114, 2014.

[3] A. Hamdan, C. Noël, J. Ghanbaja, S. Migot-Choux, and T. Belmonte, "Synthesis of platinum embedded in amorphous carbon by micro-gap discharge in heptane," Mater. Chem. Phys., vol. 142, no. 1, pp. 199-206, 2013.

[4] Y. Yang, Y. I. Cho, and A. Fridman, PLASMA in LIQUID in LIQUID. Boca Raton: CRC Press, Taylor \& Francis Group.

[5] T. Ohta, "Plasma in Agriculture," in Cold Plasma in Food and Agriculture: Fundamentals and Applications, Elsevier Inc., 2016, pp. 205-221.

[6] N. N. Misra, O. Schlüter, and P. J. Cullen, "Plasma in Food and Agriculture," in Cold Plasma in Food and Agriculture: Fundamentals and Applications, 2016, pp. 1-16.

[7] M. Ito, T. Ohta, and M. Hori, "Plasma agriculture," J. Korean Phys. Soc., vol. 60, no. 6, pp. 937-943, 2012.

[8] P. J. Bruggeman et al., "Plasma-liquid interactions: A review and roadmap," Plasma Sources Sci. Technol., vol. 25, no. 5, 2016.

[9] K. D. Weltmann, E. Kindel, T. von Woedtke, M. Hähnel, M. Stieber, and R. Brandenburg, “Atmospheric-pressure plasma sources: Prospective tools for plasma medicine," Pure Appl. Chem., vol. 82, no. 6, pp. 1223-1237, 2010.

[10] S. Maheux et al., "Formation of ammonium in saline solution treated by nanosecond pulsed cold atmospheric microplasma: A route to fast inactivation of E. coli bacteria," RSC Adv., vol. 5, no. 52, pp. 42135-42140, 2015.

[11] A. Schütze, J. Y. Jeong, S. E. Babayan, J. Park, G. S. Selwyn, and R. F. Hicks, “The atmospheric-pressure plasma jet: A review and comparison to other plasma sources," IEEE Trans. Plasma Sci., vol. 26, no. 6, pp. 1685-1694, 1998.

[12] P. Bruggeman, D. Schram, M. Á. González, R. Rego, M. G. Kong, and C. Leys, "Characterization of a direct dc-excited discharge in water by optical emission 
spectroscopy," Plasma Sources Sci. Technol., vol. 18, no. 2, 2009.

[13] X. P. Lu and M. Laroussi, "Atmospheric pressure glow discharge in air using a water electrode," IEEE Trans. Plasma Sci., vol. 33, no. 2 I, pp. 272-273, 2005.

[14] H. Wang, R. J. Wandell, K. Tachibana, J. Voráč, and B. R. Locke, "The influence of liquid conductivity on electrical breakdown and hydrogen peroxide production in a nanosecond pulsed plasma discharge generated in a water-film plasma reactor," Journal of Physics D: Applied Physics,vol. 52, no. 7, pp.075201, 2018.

[15] T. Ishijima, H. Hotta, H. Sugai, and M. Sato, "Multibubble plasma production and solvent decomposition in water by slot-excited microwave discharge," Appl. Phys. Lett., vol. 91, no. 12, pp. 1-4, 2007.

[16] A. Hamdan, K. Čerṇevičs, and M.S. Cha, "The effect of electrical conductivity on nanosecond discharges in distilled water and in methanol with argon bubbles, "Journal of Physics D: Applied Physics, vol. 50, no. 18, pp.185207, 2017.

[17] V. A. Kolikov et al., "Prolonged microbial resistance of water treated by a pulsed electrical discharge," Tech. Phys., vol. 52, no. 2, pp. 263-270, 2007.

[18] V. A. Kolikov, V. E. Kurochkin, L. K. Panina, and F. G. Rutberg, "Pulse Electric discharges and the prolonged microbial resistance of water," Dokl Biol Sci, vol. Jul-Aug, no. 403, pp. 279-281, 2005.

[19] P. Lukes et al., "Generation of chemically active species by electrical discharges in water," Plasma Sources Sci. Technol., vol. 8, pp. 258-258, 1999.

[20] J.-L. Liu, H.-W. Park, A. Hamdan, and M. S. Cha, "In-liquid arc plasma jet and its application to phenol degradation," J. Phys. D. Appl. Phys., vol. 51, no. 114005, 2018.

[21] A. Hamdan, J. L. Liu, and M. S. Cha, "Microwave Plasma Jet in Water: Characterization and Feasibility to Wastewater Treatment," Plasma Chem. Plasma Process., vol. 38, no. 5, pp. 1003-1020, 2018.

[22] M. A. Malik, "Water purification by plasmas: Which reactors are most energy efficient?," Plasma Chem. Plasma Process., vol. 30, no. 1, pp. 21-31, 2010.

[23] R. P. Cardoso, T. Belmonte, P. Keravec, F. Kosior, and G. Henrion, "Influence of impurities on the temperature of an atmospheric helium plasma in microwave resonant cavity," J. Phys. D. Appl. Phys., vol. 40, 1394-1400, 2007

[24] P. Bruggeman and R. Brandenburg, "Atmospheric pressure discharge filaments and 
microplasmas: Physics, chemistry and diagnostics," J. Phys. D. Appl. Phys., vol. 46, no. 46, 2013.

[25] C.-J. Chen, S.-Z. Li, J. Zhang, and D. Liu, "Temporally resolved diagnosis of an atmospheric-pressure pulse- modulated argon surface wave plasma by optical emission spectroscopy," J. Phys. D Appl. Phys., vol. 51, no. 2, 2017.

[26] M. Gigosos A. and C. Valentín, "New plasma diagnosis tables of hydrogen Stark broadening including ion dynamics," J. Phys. B At. Mol. Opt. Phys., vol. 29, no. 20, p. 4795, 1996.

[27] P. Bruggeman and D. C. Schram, "On OH production in water containing atmospheric pressure plasmas," Plasma Sources Sci. Technol., vol. 19, no. 4, 2010.

[28] J. A. Bravo, R. Rincón, J. Muñoz, A. Sánchez, and M. D. Calzada, "Spectroscopic Characterization of Argon-Nitrogen Surface-Wave Discharges in Dielectric Tubes at Atmospheric Pressure," Plasma Chem. Plasma Process., vol. 35, no. 6, pp. 993-1014, 2015.

[29] A. Durocher-Jean, N. Delnour, and L. Stafford, "Influence of N2, O2, and H2 admixtures on the electron power balance and neutral gas heating in microwave Ar plasmas at atmospheric pressure," J. Phys. D. Appl. Phys. 2019, in press. [https://doi.org/10.1088/1361].

[30] A. Hamdan, C. Gagnon, M. Aykul, and J. Profili "Characterization of a microwave plasma jet (TIAGO) in-contact with water: application in degradation of methylene blue dye" Plasma Processes and Polymers, 2019, submitted. 


\section{Figure captions:}

Figure 1. Schematic of the experimental setup used to create submerged MWPJ: a) 3D view and b) $2 \mathrm{D}$ view. The zone delimited by dashed-blue line shows where the high-speed images are acquired.

Figure 2. Comparison of experimental and simulated spectra of $\mathrm{OH}(\mathrm{A}-\mathrm{X})$ at a) Ar flow rate $=2$ $\mathrm{L} / \mathrm{min}$ and $\sigma_{\mathrm{w}}=100 \mu \mathrm{S} / \mathrm{cm}$, as well as b) Ar flow rate $=0.6 \mathrm{~L} / \mathrm{min}$ and $\sigma_{\mathrm{w}}=10000 \mu \mathrm{S} / \mathrm{cm}$; $\mathrm{P}=200 \mathrm{~W}$ and water volume $=200 \mathrm{~mL}$.

Figure 3. Optical emission spectra acquired at the inlet of the liquid cell for four $\sigma_{\mathrm{w}}$ values (10, 100,1000 , and $10000 \mu \mathrm{S} / \mathrm{cm}$ ) at Ar flow rates of a) $2 \mathrm{~L} / \mathrm{min}$ and b) $0.6 \mathrm{~L} / \mathrm{min} . \mathrm{P}=200$ $\mathrm{W}$, exposure time $=1 \mathrm{~ms}$, and number of accumulations $=50$.

Figure 4. Intensity variations of $\mathrm{OH}(309 \mathrm{~nm}), \mathrm{Ar}(696.5 \mathrm{~nm}), \mathrm{H}(656.3 \mathrm{~nm}), \mathrm{O}(777 \mathrm{~nm})$, and K $(769.8 \mathrm{~nm})$ spectroscopic bands as a function of $\sigma_{\mathrm{w}}$ for Ar flow rates of a) $2 \mathrm{~L} / \mathrm{min}$ and b) $0.6 \mathrm{~L} / \mathrm{min} . \mathrm{P}=200 \mathrm{~W}$ and water volume $=200 \mathrm{~mL}$.

Figure 5. Variation of $\mathrm{OH}$ rotational temperature as a function of $\sigma_{\mathrm{w}}$ for two Ar flow rates; $\mathrm{P}=$ $200 \mathrm{~W}$ and water volume $=200 \mathrm{~mL}$.

Figure 6. a) Typical experimental and simulated profile of the $\mathrm{H} \beta$ line. b) Variation of the electron density (ne) as a function of $\sigma_{\mathrm{w}} . \mathrm{P}=200 \mathrm{~W}$, water volume $=200 \mathrm{~mL}$, and Ar flow rate $=$ $2 \mathrm{~L} / \mathrm{min}$.

Figure 7. Plasma-bubble dynamics for various $\sigma_{w}$, at Ar flow rate $=0.6 \mathrm{~L} / \mathrm{min}, \mathrm{P}=200 \mathrm{~W}$, and water volume $\left.\left.\left.=200 \mathrm{~mL}: \mathbf{a}) \sigma_{\mathrm{w}}=10 \mu \mathrm{S} / \mathrm{cm}, \mathbf{b}\right) \sigma_{\mathrm{w}}=100 \mu \mathrm{S} / \mathrm{cm}, \mathbf{c}\right) \sigma_{\mathrm{w}}=1000 \mu \mathrm{S} / \mathrm{cm}, \mathbf{d}\right)$ $\sigma_{\mathrm{w}}=5000 \mu \mathrm{S} / \mathrm{cm}$, and e) $\sigma_{\mathrm{w}}=10000 \mu \mathrm{S} / \mathrm{cm}$.

Figure 8. Plasma-bubble dynamics for various $\sigma_{\mathrm{w}}$, at Ar flow rate $=0.8 \mathrm{~L} / \mathrm{min}, \mathrm{P}=200 \mathrm{~W}$ and water volume $=200 \mathrm{~mL}$.

Figure 9. Plasma-bubble dynamics recorded at Ar flow rates of a) $1 \mathrm{~L} / \mathrm{min}$ and b) $2 \mathrm{~L} / \mathrm{min}$, for various $\sigma_{\mathrm{w}}(\mathrm{P}=200 \mathrm{~W}$ and water volume $=200 \mathrm{~mL})$.

Figure 10. Emission intensity variations of $\mathrm{OH}(309 \mathrm{~nm}), \mathrm{Ar}(696.5 \mathrm{~nm}), \mathrm{H}(656.3 \mathrm{~nm}), \mathrm{O}(777$ $\mathrm{nm})$, and $\mathrm{K}(769.8 \mathrm{~nm})$ as a function of $\mathrm{N}_{2}$ percentage for water samples with electrical conductivities of $10000 \mu \mathrm{S} / \mathrm{cm}$ (a) and $10 \mu \mathrm{S} / \mathrm{cm}$ (b) (spectra recorded at Ar- $\mathrm{N}_{2}$ flow rate of $2 \mathrm{~L} / \mathrm{min}$ ). Variations of rotational temperature (c) and electron density (d) variation as a function of $\mathrm{N}_{2}$ percentage in Ar. $\mathrm{P}=200 \mathrm{~W}$, water volume $=200 \mathrm{~mL}$.

Figure 11. Plasma-bubble dynamics at $\mathrm{t}=18 \mathrm{~ms}$ for varying conditions of $\sigma_{\mathrm{w}}$ and $\mathrm{N}_{2}$ percentage. Flow rate $=2 \mathrm{~L} / \mathrm{min}, \mathrm{P}=200 \mathrm{~W}$, and water volume $=200 \mathrm{~mL}$.

Figure 12. Variation of normalized MB absorbance as a function of $\sigma_{w}$ for varying conditions of $\% \mathrm{~N}_{2}$ added and flow rate. 


\section{SUPPLEMENTAL MATERIAL}

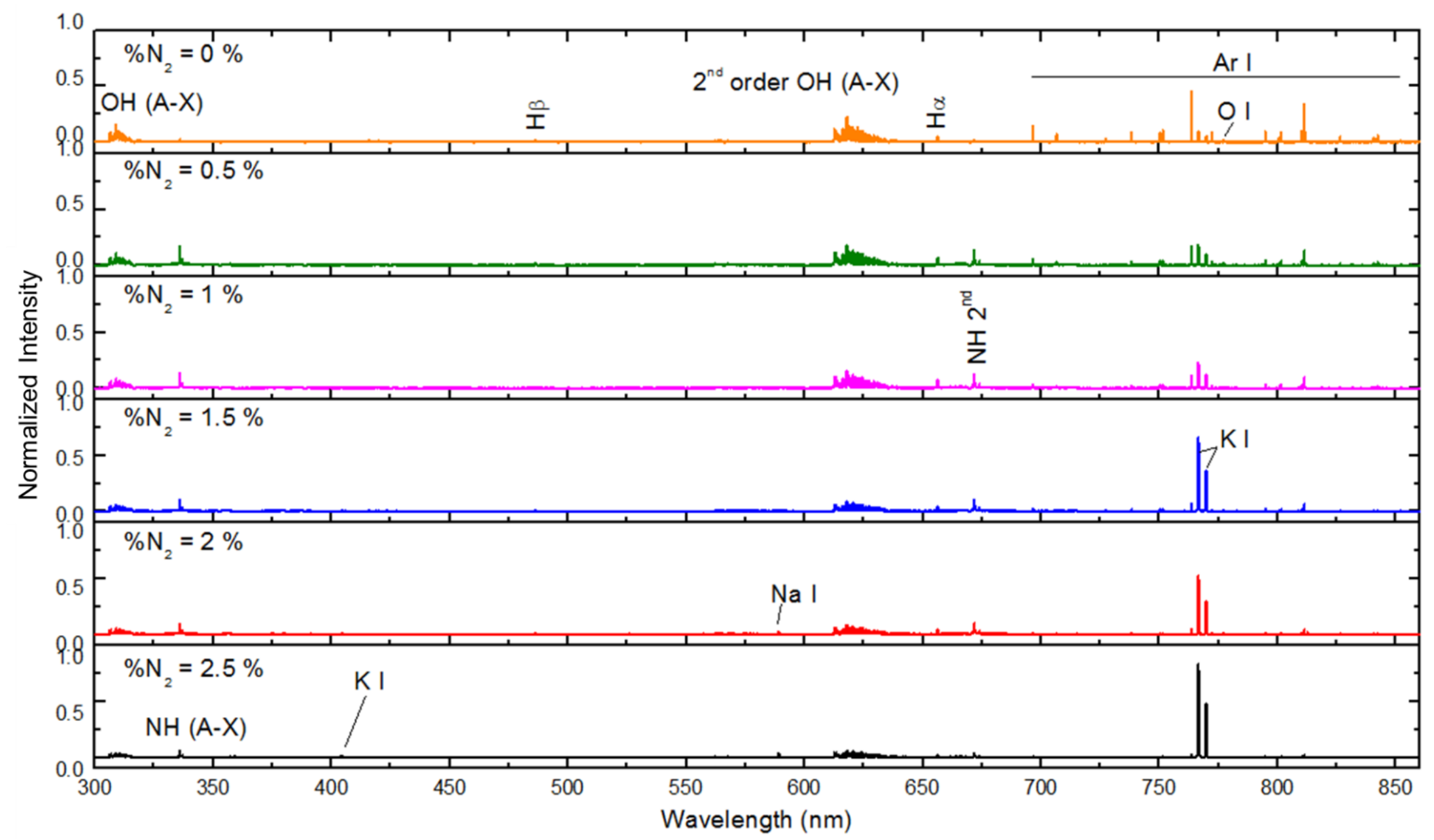

Supplemental material 1. Optical emission spectra acquired at the inlet of the MWPJ to the liquid cell for six $\mathrm{N}_{2}$ percentages $(0,0.5$, $1,1.5,2$, and $2.5 \%$ ). Flow rate $=2 \mathrm{~L} / \mathrm{min}, \sigma_{\mathrm{w}}=10000 \mu \mathrm{S} / \mathrm{cm}, \mathrm{P}=200 \mathrm{~W}$, exposure time $=1 \mathrm{~ms}$, and number of accumulations $=50$. 